Amasya İlahiyat Dergisi - Amasya Theology Journal

ISSN 2667-7326 | e-ISSN 2667-6710

Aralık / December 2020, 15: 43-76

\title{
Üstün Zekâlı Öğrencilerin Din Kültürü ve Ahlak Bilgisi Dersine İlişkin Tutumlarının İncelenmesi*
}

\author{
Cemal TOSUN \\ Prof. Dr., Ankara Üniversitesi, İlahiyat Fakültesi, \\ Din Eğitimi Anabilim Dalı \\ Prof. Dr., Ankara University, Faculty of Divinity, \\ Department of Religious Education \\ Ankara, Turkey \\ cemal.tosun@divinity.ankara.edu.tr \\ orcid.org/0000-0002-9941-4769
}

\section{Hasan SÖZEN}

Dr. Öğr. Üyesi, Bayburt Üniversitesi, İlahiyat Fakültesi,

Din Eğitimi Anabilim Dalı

Assistant Professor, Bayburt University, Faculty of Theology,

Department of Religious Education

Bayburt, Turkey

hasan.sozen@mail.com

orcid.org/0000-0002-3141-2994

* Bu araştırma, Bayburt Üniversitesi Bilimsel Araştırmalar Etik Kurulu'nun 03.03.2020 tarih ve 2020/4 sayılı araştırma izni ile yapılmıştır. Çalışmanın verileri, 2020 yılı Mart ayında Milli Eğitim Bakanlığı Özel Eğitim ve Rehberlik Hizmetleri Genel Müdürlüğü tarafından düzenlenen 'Üstün Yetenekli Öğrenciler İçin Din Kültürü ve Ahlak Bilgisi Dersi Öğretim Programları Geliştirme Çalıştayı' kapsamında öğrencilerin ihtiyaçlarını belirleme çerçevesinde toplanmıştır.

The Ethics Committee of Scientific Research dated 03.03.2020 and numbered 2020/4. The data of the study were collected in the month of March 2020, within the scope of determining the needs of students in the framework of "Workshop for Curriculum Development of Religious Culture and Ethics Course for Gifted Students" organized by the, Ministry of National Education, General Directorate of Special Education.This research was carried out with the permission of Bayburt University, 
44 । C. TOSUN \& H. SÖZEN \& Y. İPEK \& V. ŞIMŞEK / Üstün Zekâlı Öğrencilerin Din Kültürü ve Ahlak Bilgisi Dersine İlişkin Tutumlarının İncelenmesi

\section{Yasemin İPEK}

Arş. Gör., Pamukkale Üniversitesi, İlahiyat Fakültesi, Din Eğitimi Anabilim Dalı

Research Assistant, Pamukkale University, Faculty of Theology, Department of Religious Education

Denizli, Turkey yaseminipek2004@gmail.com orcid.org/0000-0002-5218-0870

\section{Vahdeddin ŞİMŞEK}

Arş. Gör., Kırıkkale Üniversitesi, İslami İlimler Fakültesi, Din Bilimleri Anabilim Dalı

Research Assistant, Kırıkkale University, Faculty of Islamic Sciences, Department of Religious Sciences Kırikkale, Turkey v.simsek@kku.edu.tr orcid.org/0000-0002-3973-850X

\section{Makale Bilgisi / Article Information}

Makale Türü / Article Types: Araştırma Makalesi / Research Article

Geliş Tarihi / Received: 03 Eylül / September 2020

Kabul Tarihi / Accepted: 22 Ekim / October 2020

Yayın Tarihi / Published: 30 Aralık / December 2020

Yayın Sezonu / Pub. Date Season: Aralık / December

Sayı / Issue: 15 Sayfa / Pages: 43-76

Atıf / Cite as: Tosun, Cemal - Sözen, Hasan - İpek, Yasemin - Şimşek, Vahdeddin. "Üstün Zekâlı Öğrencilerin Din Kültürü ve Ahlak Bilgisi Dersine İlişkin Tutumlarının İncelenmesi [Analysing of the Attitudes of Gifted Students for the Course of Religious Culture and Ethics]". Amasya Illahiyat Dergisi-Amasya Theology Journal 15 (December 2020): 43-76.

https://doi.org/10.18498/amailad.788278.

İntihal / Plagiarism: Bu makale, en az iki hakem tarafından incelendi ve intihal içermediği teyit edildi. / This article has been reviewed by at least two referees and scanned via a plagiarism software.

Copyright $\odot$ Published by Amasya Üniversitesi, İlahiyat Fakültesi / Amasya University, Faculty of Theology, Amasya, 05100 Turkey. All rights reserved. https://dergipark.org.tr/amailad. 
C. TOSUN \& H. SÖZEN \& Y. İPEK \& V. ŞIMŞEK / Analysing of the Attitudes of Gifted Students for the Course of Religious Culture and Ethics | 45

\section{Analysing of the Attitudes of Gifted Students for the Course of Religious Culture and Ethics}

\section{Abstract}

People with high intelligence levels are the most important human resource in the society which they live in. Societies that have discovered the importance of potential of gifted students, can progress much higher than their peers in the fields of studies on gifted children and their education. In this context, in recent years the educational activities for gifted students have increased in Turkey as well as all over the world. At this point, Science and Art Centers (BILSEM) were established to aim providing education for individuals with superior abilities and intelligence. The gifted students who are educated in these centers can also receive education at school like other students. One of these courses is Religious Culture and Ethics. However, there are no studies to determine the attitudes of students with these characteristics towards the course of Religious Culture and Ethics.

In this context, the aim of the research is to examine the general attitudes of gifted students about the course of Religious Culture and Ethics with different variables. On the other hand, other aims of the research are to draw attention on the gap in the field related to gifted students, to demonstrate that more in-depth studies are needed to determine the interests and needs of gifted students in the field of teaching religion and ethics, and to lay the groundwork for new researches on this issue.

The study used the model of literature review from quantitative research methods. The study group consists of secondary and high school students who are diagnosed as "gifted" by the Ministry of National Education, General Directorate of Special Education. The research data in research was collected in the 2019-2020 academic year. The SPSS package program was used to analyse the data obtained. For the testing reliability of the scale based on the data obtained, the internal consistency coefficient (Cronbach's Alpha) was calculated and the value of Cronbach' Alpha was calculated to be 0,05. In addition, the descriptive statistics such as percentage, frequency, and arithmetic mean are also included to summarize the data.

As a result of the analysis, it was concluded that the attitudes of gifted students in the study regarding the courses of Religious Culture and Ethics were positive. It was resulted that their attitudes did not differ statistically according to gender and maternal learning status, but differed statistically according to the paternal educational background, level of class and income. 
46 | C. TOSUN \& H. SÖZEN \& Y. IPEK \& V. ŞIMŞEK / Üstün Zekâlı Öğrencilerin Din Kültürü ve Ahlak Bilgisi Dersine İlişkin Tutumlarının İncelenmesi

At this point, it was found important the determining of expectation of students themselves and their parents from the curriculum, teachers, teaching activities, materials, and methods of the course to review for the positively increasing attitudes of both gifted students and students with normal intelligence towards to the course. Another important result of this research, the priority recommended is to conduct qualitative studies that will provide more in-dept data to support the quantitative data. Another important recommendation is to develop the differentiated DKAB curriculum for gifted students taking into account the recommendations of relevant results. It is also important to develop the course materials that take into account their learning capacities, high-level thinking skills, interests and needs to ensure that educational activities for gifted students are carried out in integrity. In all educational activities that will be designed for gifted students, care should be taken to choose and develop approaches, methods-techniques and materials that will make it possible to build knowledge up, not present pattern knowledge.

Keywords: Religious Education, Giftedness, Student, Attitude, Religious Culture and Ethics.

\section{Üstün Zekâlı Öğrencilerin Din Kültürü ve Ahlak Bilgisi Dersine İlişkin Tutumlarının İncelenmesi}

\section{Öz}

Zekâ düzeyi yüksek kişiler, yaşadıkları toplumun en önemli insan kaynağıdır. Üstün zekâlı öğrencilerin potansiyelinin önemini fark eden toplumlar üstün yetenekli çocuklara ve bu çocukların eğitimlerine yönelik çalışmalara daha da hız vermiştir. Bu bağlamda son yıllarda üstün yetenekli öğrencilere yönelik eğitim faaliyetleri tüm dünyada olduğu gibi Türkiye'de de artmıştır. Bu noktada Bilim ve Sanat Merkezleri (BİLSEM) kurulmuş ve üstün yetenek ve zekâya sahip bireylere eğitim verilmesi amaçlanmıştır. Bu merkezlerde eğitim gören üstün yetenekli öğrenciler hem bu merkezlerde hem de diğer öğrenciler gibi okulda da eğitim görmektedir. Eğitim alınan derslerden biri de Din Kültürü ve Ahlâk Bilgisidir. Ancak bu özelliklere sahip öğrencilerin Din Kültürü ve Ahlâk Bilgisi dersine yönelik tutumlarının belirlenmesine dair çalışma bulunmamaktadır.

Bu bağlamda araştırmanın amacı, üstün zekâlı öğrencilerin Din Kültürü ve Ahlak Bilgisi (DKAB) dersine ilişkin genel tutumlarını farklı değişkenlere göre incelemektir. Diğer taraftan, üstün zekâlı öğrencilerle ilgili alan yazındaki söz konusu boşluğa dikkat çekmek, üstün zekâlı öğrencilerin din ve ahlak öğretimi 

the Course of Religious Culture and Ethics | 47

alanındaki ilgi ve ihtiyaçlarının belirlenmesine ilişkin daha derinlemesine çalışmalara ihtiyacı ortaya koymak ve bu konuda yeni çalışmalara zemin hazırlamaktır.

Çalışmada nicel araştırma yöntemlerinden ilişkisel tarama modeli kullanılmıştır. Çalışma grubunu, Milli Eğitim Bakanlığı, Özel Eğitim ve Rehberlik Hizmetleri Genel Müdürlüğünce "üstün zekâlı" olarak tanılanan ortaokul ve lise öğrencileri oluşturmaktadır. Söz konusu araştırma verileri 20192020 eğitim ve öğretim yılında toplanmıştır. Verilerin analizinde SPSS paket programından yararlanılmıştır. Ölçeğin, elde edilen veriler üzerinden güvenirliğini test etmek üzere iç tutarlılık katsayısı (Cronbach Alfa) hesaplanmış, Cronbach Alfa değeri 0,95 olarak saptanmıştır. Bununla birlikte yüzde, frekans, aritmetik ortalama gibi betimsel istatistiklere yer verilmiştir. Öğrencilerin DKAB dersine ilişkin tutumlarının cinsiyet, sınıf düzeyi, gelir durumu, anne ve baba öğrenim durumu değişkenlerine göre incelenmesi için öncelikle veri setinin parametrik test varsayımlarını karşılayıp karşılamadı̆̆ına bakılmıştır. $\mathrm{Bu}$ amaçla yapılan istatiksel işlemler parametrik testlerin kullanımının uygunluğunu göstermiştir. İki örneklem grubundan elde edilen ortalama değerleri kıyaslamak üzere ilişkisiz (bağımsız) örneklemler t testi; ikiden fazla sayıda örneklem grubundan elde edilen ortalama değerleri kıyaslamak için tek faktörlü varyans analizi (ANOVA) testi kullanılmıştır.

Yapılan analizlerden, üstün zekâlı öğrencilerin DKAB derslerine ilişkin tutumlarının olumlu olduğu; söz konusu tutumlarının cinsiyet ve anne öğrenim durumuna göre istatistiksel olarak anlamlı düzeyde farklılaşmadığı, ancak sınıf düzeyi, gelir ve baba öğrenim durumlarına göre farklılaştığ1 sonucuna ulaşılmıştır.

Bu noktada gerek üstün zekâlı öğrencilerin gerekse normal zekâ gelişim özelliği gösteren öğrencilerin DKAB dersine ilişkin tutum düzeylerini olumlu yönde arttırmak amacıyla öğrencilerin kendilerinin ve velilerinin dersin öğretim programından, öğretmenlerinden, öğretim etkinliklerinden, materyallerinden ve yöntemlerinden beklentilerinin neler olduğunun tespit edilmesi ve söz konusu hususların gözden geçirilmesi ve iyileştirilmesi açısından önemlidir. Bu çalışmanın sonucunda öncelikli olarak önerilen husus, elde edilen nicel bulguları desteklemek üzere daha derinlemesine veri sağlayacak nitel çalışmaların yapılmasıdır. Bu bağlamda önerilen bir diğer önemli husus da ilgili araştırmalardan elde edilen tespit ve öneriler dikkate alınarak üstün zekâlı olarak belirlenmiş öğrencilere yönelik farklılaştırılmış DKAB öğretim programlarının geliştirilmesidir. Üstün zekâlı öğrencilere yönelik eğitim 
48 । C. TOSUN \& H. SÖZEN \& Y. İPEK \& V. ŞIMŞEK / Üstün Zekâlı Öğrencilerin Din Kültürü ve Ahlak Bilgisi Dersine İlişkin Tutumlarının İncelenmesi

faaliyetlerinin bir bütünlük içerisinde yürütülmesini sağlamak üzere bu öğrencilerin öğrenme kapasitelerini, üst düzey düşünme becerilerini, ilgi ve ihtiyaçlarını dikkate alan ders materyallerinin geliştirilmesi de önem arz etmektedir. Üstün zekâlı öğrencilere yönelik tasarlanacak eğitim ve öğretim sürecinde bilgiyi hazır sunan değil, bilgiyi yapılandırmayı mümkün kılacak yaklaşım, yöntem-teknik ve materyallerin seçilmesine özen gösterilmelidir.

Anahtar Kelimeler: Din Eğitimi, Üstün Zekâ, Öğrenci, Tutum, Din Kültürü ve Ahlak Bilgisi.

\section{Giriş}

İnsanın düşünme, akıl yürütme, objektif gerçekleri algılama, yargılama ve sonuç çıkarma yeteneklerinin tamamına verilen bir isim olarak zekâ (TDK, 2020), eğitim ve gelişim psikolojisinde ele alınan konuların başında gelmektedir. Zekâ düzeyleri yüksek insanlar, içinde yaşadıkları topluma önemli katkılarda bulanabilir. Akranlarına göre çok daha hızlı öğrenebilen, ilgilendikleri alanlarda kendi yaşıtlarına göre çok daha yüksek bir aşama kat edebilen üstün zekâlı öğrencilerin sahip oldukları potansiyeli keşfeden toplumlar, üstün zekâlı çocuklara ve bunların eğitimine dönük çalışmalara hız vermiştir.

Literatürde "üstün zekâlı", "üstün yetenekli" ve "özel yetenekli" kavramlarının genellikle birlikte kullanıldığı tespit edilmiştir. Üstün zekâlı, üstün yetenekli veya özel yetenekli öğrencilere dönük araştırmalara bakıldığında; üstün yetenekli, özel yetenekli ve üstün zekâlı kavramlarıyla ilgili genel ve ortak bir tanımın bulunmadığı, söz konusu kavramların genellikle birbirlerinin yerine kullanıldığı da görülmüştür (Bk. Özel Yetenekli Bireyler Strateji ve Uygulama Planı 2013-2017). "Üstün zekâ" ve "üstün özel yetenek" kavramları, Üstün Yetenekli Çocuklar ve Eğitimleri Komisyonu Raporunda "üstün yetenek" başlığı altında toplanmış ve şu şekilde tanımlanmıştır: "Üstün yetenekliler, genel ve/veya özel yetenekleri açısından, yaşıtlarına göre yüksek düzeyde performans gösterdiği konunun uzmanları tarafından belirlenmiş kişilerdir" (Birinci Özel Eğitim Konseyi Ön Raporu, 1991). Bir başka tanıma göre üstün veya özel yetenekli çocuklar, seçkin yeteneklerinden dolayı yüksek seviyeli iş yapmaya yeterli olan; söz konusu yetenekleri alanında kabul görmüş kimseler tarafından tanılanmış olan çocuklardır (Clark, 2015, 30). 
Kirk ve Gallagher'a göre üstün veya özel yetenekli çocuklar; entelektüel, yaratıcı, sanat veya liderlik gibi alanlarda yüksek performans kapasitesi gösteren veya bu kapasitelerini tamamen geliştirmek için özel akademik etkinliklere ve faaliyetlere ihtiyaç duyan çocuklardır (Kirk - Gallagher, 1989).

Üstün veya özel yetenekli çocuklar, Üstün Zekâlı ve Yetenekli Çocuklar Dünya Konseyi tarafından belirlenen zekâ ve diğer yetenek alanlarında başarı gösteren veya söz konusu başarıyı gösterme potansiyeline sahip olan bireylerdir. Bunlar; Genel Zihinsel Yetenek, Özel Akademik Yetenek, Yaratıcı ve Üretici Düşünme, Liderlik Yeteneği, Görsel ve Sahne Sanatları ile Psiko-Motor (Devinimsel) Yetenek alanlarıdır (Clark, 2015, 30; Conklin - Frei, 2016, 17).

Üstün yetenekli öğrenciler, Bilim Sanat Merkezi (BİLSEM) Yönergesinde (2019, 393) "yaşıtlarına göre daha hızlı öğrenen; yaratıcılık, sanat, liderliğe ilişkin kapasitede önde olan, özel akademik yeteneğe sahip, soyut fikirleri anlayabilen, ilgi alanlarında bağımsız hareket etmeyi seven ve yüksek düzeyde performans gösteren bireylerdir" şeklinde tanımlanmaktadır. Söz konusu yönerge incelendiğinde $M E B$ 'in üstün yetenekli öğrencileri, sahip oldukları yeteneklerine göre, genel zihinsel, görsel sanatlar ve müzik yetenek alanı olmak üzere üç temel alanda kategorize ettiği, incelediği ve değerlendirdiği görülmektedir.

$\mathrm{Bu}$ araştırmada yer alan çalışma grubu T.C. Milli Eğitim Bakanlığ Özel Eğitim ve Rehberlik Hizmetleri Genel Müdürlüğü tarafından "genel zihinsel yetenek" alanında üstün yetenekli olarak tanılanmış ortaokul ve lise düzeyindeki öğrencilerden seçilmiştir. Çalışma grubunun genel zihinsel yetenek alanında başarı gösteren öğrencilerden oluşmasından da hareketle çalışmanın genelinde bu öğrenciler için üstün zekâlı nitelemesinin kullanımı tercih edilmiştir.

Üstün zekâlı çocuklar; bazı özelliklerinin dağılımı, yoğunluğu ve kompozisyonu açısından diğer çocuklardan farklılık göstermektedir. Bunlar çok daha kısa bir sürede öğrenebilen, karmaşık ve soyut kavram ve fikirleri algılayabilen, ilgilendikleri alanlarda kendi yaşıtlarına göre çok daha yüksek bir aşama kat edebilen bireylerdir (Çatalbaş, 1998; Winebrenner, 2000, 54; Akarsu, 2001; Neumeister vd. 2007, 495).

Üstün zekâlı öğrenciler, bilgiyi diğerlerinden çok daha hızlı işleyebilmekte, problemleri çok daha çabuk çözüme 
50 । C. TOSUN \& H. SÖZEN \& Y. İEK \& V. ŞIMŞEK / Üstün Zekâlı Öğrencilerin Din Kültürü ve Ahlak Bilgisi Dersine İlişkin Tutumlarının İncelenmesi

kavuşturabilmektedir. Her ne kadar bazı alanlarda diğer çocuklardan çok daha üstün beceri ve yeteneklere sahip olsalar da birtakım öğrenme sorunları yaşayabilmekte, genel müfredatın dışında hizmet ve etkinliklere gereksinim duyabilmektedir (Çatalbaş, 1998). Bu durum, üstün zekâlı çocukların kendi ilgi ve yeteneklerine uygun öğrenme ortam ve olanaklarını, eğitim sürecinde farklılaştırılmış öğretim programlarını kaçınılmaz kılmaktadır. Aksi bir durum sahip oldukları potansiyelin, ilgi ve motivasyonun kaybedilmesine neden olmaktadır (Conklin - Frei, 2016, 20-25). Bunun için üstün zekâlı çocukların, diğer çocuklarla sahip oldukları ortak ilgi ve ihtiyaçlarının yansıra, onlardan farklı olarak sahip oldukları niteliklerinin tespit edilmesi tüm öğretim alanları/branşlar açısından önem arz etmektedir

Bireysel farklılıkların, birçok öğrenme alanını etkilediği gibi din ve ahlak öğrenme alanlarını da etkilemesi kaçınılmazdır. Çünkü birey bir bütündür ve onda meydana gelen değişme, tüm gelişim alanlarının etkileşiminin ürünüdür. Diğer bir ifadeyle farklı gelişim alanları, birbiri ile ilintilidir ve bireylerin bilişsel, sosyal, ahlaki vs. farklı gelişim alanları bir bütünlük içerisinde değişme ve ilerleme kaydetmektedir (Atik, 2015, 731). Buradan hareketle, üstün zekâlı öğrencilerin sahip oldukları çok yönlü düşünme biçim / süreçlerinin ve karmaşık duygularının her alandaki öğrenmelere yansıması kuvvetle muhtemeldir. İnsan zekâsı, bilgi ve tecrübesi geliştikçe, çok yönlü düşünme becerisi artmakta ve bu durum her alanda olduğu gibi ahlaki (Güngör, 2008, 29) ya da dini alandaki duygu, düşüncelerinde ve yargılamalarında hesaba kattıkları faktörleri de karmaşıklaştırabilmekte ve zenginleştirebilmektedir.

Üstün zekâlı çocuklarda ahlak gelişimi üzerine yapılan yabancı kaynaklı bazı araştırma sonuçları, çocukların önemli bir kısmında küçük yaşlardan itibaren ahlaki duyarlılığın açık izlerinin görüldügünü ortaya koymaktadır. Ayrıca, bu yönde yapılan diğer araştırmalarda üstün zekâlı çocukların dini ve felsefi konularda da normal zekâ gelişim özellikleri gösteren yaşıtlarına göre daha üst düzey düşünme becerilerine sahip oldukları tespit edilmiştir (Gündüz, 2018, 266). Nitekim ülkemizde genel olarak üstün/özel yetenekliler veya daha özel bir sınırlama ile üstün zekâlı öğrencilerin dini ve ahlaki alandaki eğilimlerini, bireysel farklılıklarını ve bunların öğrenme ortamlarına yansımalarını inceleyen bilimsel saha çalışmalarına rastlanılmamaktadır. Din eğitimi alanında bu tür araştırma verilerine 

the Course of Religious Culture and Ethics I 51

rastlanılmaması gerek bu çocukların din ve ahlaki alanındaki eğilimlerini gerekse bu özelliklerinin öğrenme alanlarına yansıması konusunda bir tartışmanın yapılmasını bile sınırlandırmaktadır. Hâlbuki İslam eğitim tarihimizde öğrencilerin kişisel özelliklerinin neler olduğunun bilinmesi, kabiliyetlerine uygun bir şekilde yönlendirilmesi ve eğitimlerinde ferdi farklılıklarının göz önünde bulundurulmasının gerekliliği üzerinde durulmuştur (Bayraktar, 2015, 37-43).

Üstün zekâlı öğrencilerin ilgi ve ihtiyaçlarına göre din ve ahlak öğretiminin sağlanmasının ön koşulu ise kendi doğasında yer alan farklılıklardan ve içerisinde bulundukları toplumun kültürel kodlardan hareketle dini ve ahlaki alandaki hazırbulunuşluklarının, öğrenmelere ilişkin tutumlarının, öğrenme biçimlerinin ve bu alanda ilgi duydukları muhtevanın tespitini gerektirmektedir (Güçin - Oruç, 2015, 121). Zira ayrıntılı bir şekilde hedef kitlenin çözümlenmesi tamamlanmadan başlayan eğitimlerde bilişsel ve duyuşsal açıdan birçok sorunla karşılaşılması muhtemeldir. Konuya karşı ilgisizlik, katılıma isteksizlik, açıklamaları hafife alma, gereksiz tartışmalar, güdülenme eksikliği, bilişsel direnç, eğitimin yararını sorgulama, öğrenmeyi zaman kaybı gibi görme, sınırlı bilgiyle başkalarına bilgiçlik taslama gibi bazı olumsuzlukları beraberinde getirebilmektedir. Dolayısıyla hedef kitlenin gerek öğrenme ortamına istekli ve hazır gelmelerini sağlamak gerekse eğitsel süreçlerde öğrenmeye etkin katılım yönünde çaba göstermelerini sağlamak için her branşın kendi sınırları içerisinde hedef kitlesinin çok yönlü incelenmesi gereklidir (Şimşek, 2009, 105).

Din ve ahlak öğretiminin hedefi, öğrencilerin yeteneklerini ortaya çıkarmak, bunları geliştirmek ve temel dinî ve ahlaki ihtiyaç ve duygularını sağlıklı bir şekilde doyurmaktır. Dini ve ahlaki bilginin öğretimi en temel bireysel-insani ihtiyaçlar arasında yer almaktadır (Tosun, 2012, 94). Bu ihtiyaç hiç şüphesiz üstün zekâlı öğrenciler için de söz konusudur. Bu noktadan hareketle, üstün zekâlı öğrencilerin din eğitimi alanındaki ilgi ve ihtiyaçlarının çok yönlü belirlenmesi, daha derinlemesine ve uzun soluklu çalışmalara kapı aralayacaktır. Bu çalışmalar üstün zekâlı öğrencilere yönelik din ve ahlak alanında program geliştirmeden, materyal geliştirmeye, uygulamaya ve değerlendirmeye kadar katkı sunacaktır. Bu çalışmayla genelde araştırmacıların dikkatini bu problem alanına çekmek ve üstün zekâlı öğrencilerin DKAB dersine ilişkin genel tutumlarının nasıl olduğunun 
52 । C. TOSUN \& H. SÖZEN \& Y. IPEK \& V. ŞIMŞEK / Üstün Zekâlı Öğrencilerin Din Kültürü ve Ahlak Bilgisi Dersine İlişkin Tutumlarının İncelenmesi

ön tespitini sunmak amaçlanmıştır. Özelde ise üstün zekâlı ortaokul ve lise düzeyi öğrencilerine yönelik DKAB ders öğretim programı geliştirmede kullanılmak üzere ihtiyaç belirlenmesi amaçlanmıştır. Çalışmada söz konusu amacı gerçekleştirmek üzere aşağıdaki araştırma sorularına cevaplar aranmıştır:

- Üstün zekâlı öğrencilerin DKAB dersine ilişkin genel tutumları nasildir?

- Üstün zekâlı öğrencilerin DKAB dersine ilişkin tutumları; cinsiyet, sınıf düzeyi, gelir durumu, anne öğrenim durumu, baba öğrenim durumu değişkenlerine göre istatistiksel olarak anlamlı düzeyde farklılaşmakta mıdır?

\section{Yöntem}

\section{Araştırmanın Modeli}

Çalışmada nicel araştırma yöntemlerinden ilişkisel tarama modeli kullanılmıştır. Tarama araştırmalarıyla; kişilerin belirli konulardaki tutum, inanç, görüş, davranış ve beklentilerinin kendi koşulları içinde ve olduğu gibi tespit edilmesi amaçlanmaktadır (İslamoğlu - Alnıaçık, 2016, 99; Gürbüz - Şahin, 2004, 103). Tarama araştırmalarının bir türü olan ilişkisel taramalarda ise genellikle iki veya daha fazla değişken arasındaki ilişkilerin ortaya çıkarılması amaçlanmaktadır (Gürbüz Şahin, 2004, 105). Bu araştırmada da üstün zekâlı öğrencilerin DKAB dersine ilişkin genel tutumları ve tutumlarının bazı değişkenlerle ilişkisi betimlenmektedir.

\section{Evrem ve Örneklem/Çalışma Grubu}

Bu araştırmanın evrenini üstün zekâlı olarak tanılanmış ortaokul ve lise öğrencileri oluşturmaktadır. Araştırmanın örneklem grubunu ise T.C. Milli Eğitim Bakanlığ Özel Eğitim ve Rehberlik Hizmetleri Genel Müdürlüğü tarafından genel zihinsel alanda üstün olarak tanılanmış ve buna uygun eğitim alan 159 öğrenci oluşturmaktadır. Araştırma verileri, MEB Özel Eğitim ve Rehberlik Hizmetleri Genel Müdürlüğü tarafından düzenlenen Üstün Yetenekli Öğrencilere Yönelik Din Kültürü ve Ahlak Bilgisi Öğretim Programı geliştirme çalışmaları çerçevesinde, üstün zekâlı öğrencilerin din ve ahlak öğretimi alanına dair ihtiyaçlarını belirlemek üzere uygulanan anket ile elde edilmiştir. Söz konusu anket çalışması, 913 Mart 2020 tarihleri arasında ve bu öğrencilere yönelik faaliyet gösteren bir okulda gerçekleştirilmiştir. Ankete katılan öğrencilerin 

the Course of Religious Culture and Ethics I 53

toplam 63 ildeki Bilim ve Sanat Eğitim Merkezleri'nden bu okula geldiği tespit edilmiştir.

Çalışma grubunun belirlenmesinde olasılıklı olmayan örnekleme yaklaşımlarından amaçlı örneklem tekniği kullanılmıştır. Amaçlı örnekleme; araştırmacının kendi kişisel gözlemlerinden hareket ederek araştırma sorunsalına uygun geldiğini düşündüğü belirli özellikleri taşıyan deneklerin seçildiği örneklemedir (Gürbüz - Şahin, 2014, 130). Bu yaklaşımda örneklem belirlenirken; katılımcıların çalışmaya uygunluğunun ve erişilebilirliğinin göz önünde bulundurulması esastır (Creswell, 2017, 193-194). Araştırmanın genel evreninin üstün zekâlı öğrencileri kapsadığı dikkate alındığında; çalışma grubunun, Özel Eğitim ve Rehberlik Hizmetleri Genel Müdürlügünce üstün zekâlı olarak tanılanmış öğrencilerden oluşması araştırmanın örneklem uygunluğunu göstermesi açısından önemlidir. Ayrıca üstün zekâlı olarak tanılanmış öğrencilere ulaşılabilirliğin güç olması, araştırmada bu örnekleme tekniğinin kullanımını öncelikli kılmıştır.

Tablo 1: Katılımcılara Ait Bazı Demografik Özellikler

\begin{tabular}{cccc}
\hline Değişken Türü & Değişken Düzeyi & $\mathrm{N}$ & $\%$ \\
\hline \multirow{3}{*}{ Cinsiyet } & Kız & 61 & 38,4 \\
& Erkek & 93 & 58,5 \\
& Kayıp veri & 5 & 3,1 \\
& Toplam & 159 & 100 \\
\hline \multirow{5}{*}{ Sinıf Düzeyi } & 5. Sinif & 24 & 15,1 \\
& 6. Sinif & 17 & 10,7 \\
& 7. Sinıf & 19 & 11,9 \\
& 9. Sinıf & 25 & 15,7 \\
& 10. Sinıf & 48 & 30,2 \\
& 11. Sinif & 26 & 16,4 \\
& Toplam & $\mathbf{1 5 9}$ & $\mathbf{1 0 0}$ \\
\hline
\end{tabular}

Tablo 1'de cinsiyet durumunu ve sinıf düzeyini göstermek üzere kategorik değişkenlere ait betimleyici bilgiler verilmiştir. Cinsiyet değişkeninde 5 kişi durumunu belirtmediğinden cinsiyet değişkenine ait analizler 61'i kız 93'ü erkek olmak üzere 154 kişi üzerinden gerçekleştirilmiştir. 
54 । C. TOSUN \& H. SÖZEN \& Y. İPEK \& V. ŞİMŞEK / Üstün Zekâlı Öğrencilerin Din Kültürü ve Ahlak Bilgisi Dersine İliş̧kin Tutumlarının İncelenmesi

Sınıf düzeyi değişkeninde ise araştırmanın yapıldığı okulda henüz 8. sinıf ve 12. sınıf düzeyine geçmiş öğrenci bulunmadığından ortaokul ve lise gruplarının 1, 2 ve 3. sınıfları araştırmaya dâhil edilebilmiştir.

Tablo 2: Katılımcilara Ait Bazı Demografik Bilgiler ve Kategori Birleşimi

\begin{tabular}{|c|c|c|c|c|c|}
\hline Değişken Türü & $\begin{array}{c}\text { Değişken } \\
\text { Düzeyi }\end{array}$ & $\mathbf{N}$ & $\begin{array}{c}\text { Birleştirilmiş } \\
\text { Değişken Düzeyi }\end{array}$ & $\mathbf{N}$ & $\%$ \\
\hline \multirow{6}{*}{$\begin{array}{l}\text { Anne Öğrenim } \\
\text { Durumu }\end{array}$} & İlkokul & 3 & \multirow{3}{*}{ Lise ve altı } & \multirow{3}{*}{51} & \multirow{3}{*}{32,1} \\
\hline & Ortaokul & 10 & & & \\
\hline & Lise & 38 & & & \\
\hline & Üniversite & 92 & \multirow{3}{*}{$\begin{array}{l}\text { Üniversite ve } \\
\text { lisansüstü }\end{array}$} & \multirow{2}{*}{108} & \multirow{2}{*}{67,9} \\
\hline & Lisansüstü & 16 & & & \\
\hline & $\begin{array}{l}\text { Genel } \\
\text { Toplam }\end{array}$ & 159 & & 159 & 100 \\
\hline \multirow{4}{*}{$\begin{array}{l}\text { Baba Öğrenim } \\
\text { Durumu }\end{array}$} & $\begin{array}{l}\text { İlkokul } \\
\text { Lise }\end{array}$ & $\begin{array}{c}1 \\
26\end{array}$ & Lise ve altı & 27 & 17,0 \\
\hline & Üniversite & 100 & \multirow{3}{*}{$\begin{array}{l}\text { Üniversite ve } \\
\text { lisansüstü }\end{array}$} & \multirow{2}{*}{132} & \multirow{2}{*}{83,0} \\
\hline & Lisansüstü & 32 & & & \\
\hline & $\begin{array}{c}\text { Genel } \\
\text { Toplam }\end{array}$ & 159 & & 159 & 100 \\
\hline \multirow{5}{*}{ Gelir Durumu } & $\begin{array}{c}\text { Zengin } \\
\text { Orta üstü }\end{array}$ & $\begin{array}{c}3 \\
52\end{array}$ & \multirow[t]{2}{*}{ Orta üstü } & \multirow[t]{2}{*}{55} & \multirow[t]{2}{*}{34,6} \\
\hline & Orta & 100 & & & \\
\hline & Orta altı & 4 & \multirow[t]{2}{*}{ Orta ve altı } & \multirow[t]{2}{*}{104} & \multirow[t]{2}{*}{65,4} \\
\hline & Yoksul & 0 & & & \\
\hline & $\begin{array}{c}\text { Genel } \\
\text { Toplam }\end{array}$ & 159 & & 159 & 100 \\
\hline
\end{tabular}

Tablo 2'de anne-baba öğrenim durumlarını ve gelir durumunu gösteren kategorik değişkenlere ait betimleyici istatistikler verilmiştir. Tabloda görüldüğü gibi bazı kategorilere az katılımcı düşmüş ve bu durum bazı analizlerin yapılmasını sınırlandırmıştır. Veri setini analize daha uygun hale getirmek üzere kategori birleşimi (Pallant, 2017, 104) tercih edilmiş ve kategorik değişkenler yeniden kodlanmıştır. 


\section{Veri Toplama Araci}

Veri toplama aracı olarak kişisel bilgi formu ve Şuayip Özdemir ile Rahime Çelik tarafından geliştirilen Din Kültürü ve Ahlak Bilgisi Dersi Tutum Ölçeği -gerekli izinler alınarak- kullanılmıştır (https://toad.halileksi.net/olcek/din-kulturu-ve-ahlak-bilgisi-dersitutum-olcegi). Toplam 27 maddeden oluşan ve 531 öğrenci üzerinde uygulanan bu ölçeğin geçerlik güvenirlik çalışmaları yapılmıştır. Ölçeğin Cronbach Alpha katsayısı 0,89 olarak belirtilmiştir (Özdemir Çelik, 2017, 16).

Araştırmamız çerçevesinde çalışma grubuna uygulanan ölçekten elde edilen verilerle de ölçeğin güvenirlik kontrolü sağlanmıştır. Bu bağlamda ölçek maddeleri arasındaki iç tutarlılık düzeyi tekrar incelenmiş ve bu araştırma için Cronbach's Alpha değeri 0,95 saptanmıştır (bk. Tablo 3). Alan yazında, her ne kadar güvenirlik için 0,7 ve üzeri değerler yeterli görülse de 0,8 ve üstündeki değerlerin tercih edilmesi gerektiği belirtilmektedir (Pallant, 2017, 116). Buna göre, çalışma grubumuzun söz konusu ölçekten aldığ1 puanların yeterli olduğu sonucuna ulaşılabilir.

Tablo 3: Güvenirlik İstatistiği

\begin{tabular}{ccc}
\hline $\begin{array}{c}\text { Cronbach's } \\
\text { Alpha }\end{array}$ & $\begin{array}{c}\text { Cronbach's Alpha Based on } \\
\text { Standardized Items }\end{array}$ & N of Items \\
, 952 &, 951 & 27 \\
\hline
\end{tabular}

Araştırma grubuna uygulanan ölçekten elde edilen veri setine uygun faktör yapısını keşfetmek üzere açımlayıcı faktör analizi yapılmıştır. Verilerin açımlayıcı faktör analizine uygunluğunu anlamak için öncelikle Kaiser-Meyer-Olkin (KMO) değerlerine bakılmıştır.

Tablo 4: KMO ve Bartlett's Testi Sonuçları Kaiser-Meyer-Olkin Örneklem Yeterliliği ,925

$\begin{array}{lll} & \mathrm{X}^{2} & 2859, \\ \text { Bartlett küresellik testi } & \mathrm{Sd} & 351 \\ & \mathrm{P} & , 000\end{array}$

Tablo 4'de verilen test sonuçlarına göre ölçekten elde edilen verilerin $\mathrm{KMO}$ değerinin 0.925 olduğu ve Barlett değerinin $(p<0,05)$ anlamlı çıktığı görülmektedir. Söz konusu test değerleri göz önünde 
56 | C. TOSUN \& H. SÖZEN \& Y. IPEK \& V. ŞIMŞEK / Üstün Zekâlı Öğrencilerin Din Kültürü ve Ahlak Bilgisi Dersine İlişkin Tutumlarının İncelenmesi

bulundurularak veri yapısının faktör analizi için uygun olduğu sonucuna ulaşılmıştır.

Din Kültürü ve Ahlak Bilgisi Dersi Tutum Ölçeğinde yer alacak faktör sayısını belirlemek üzere AFA testi yapılmıştır. Yapılan AFA testi sonucunda faktörlerin öz değerlerine, öz değerlerinin açıkladıkları birikimli varyans miktarına ve serpilme grafiğine bakılmıştır. Öz değeri en az 1 olan 4 faktörün olduğu ortaya çıkmıştır (bk. tablo 5). Ancak ilk faktörün toplam varyansı tatmin edici bir düzeyde açıkladığı görülmüştür. $\mathrm{Bu}$ durum yapının tek faktörlü olarak nitelendirilebileceğini ortaya çıkarmış ve serpilme grafiği ile kararın desteklenmesi sağlanmıştır. Zira ilk faktörün bir sonraki faktörün 2-3 katından fazla olduğu durumlarda yapının tek faktörlü nitelendirilebileceği (Erkuş, 2016, 95) veya birikimli varyans miktarının toplam varyansın \%40-\%60 arasındaki miktarın açıklandığ1 yere kadar olan faktörlerin modele dâhil edilmesinin uygun olduğu belirtilmektedir (Karagöz, 2016, 880). Zira tablo 5'de görüldügü gibi yapılan AFA testinde ilk faktörün kendisinden sonraki faktörün 2-3 katından fazla olduğu ya da toplam varyansın tek başına \%47'sini açıkladığı ortaya çıkmıştır.

Tablo 5: DKAB Dersi Tutum Ölçeği öz değeri 1 ve üzerinde olan faktörler

\begin{tabular}{cccc}
\hline Faktör & Özdeğer & $\begin{array}{c}\text { Varyans } \\
\text { Yüzdesi (\%) }\end{array}$ & $\begin{array}{c}\text { Toplam Varyans } \\
\text { Yüzdesi (\%) }\end{array}$ \\
1 & 12,793 & 47,383 & 47,383 \\
2 & 1,889 & 6,997 & 54,380 \\
3 & 1,530 & 5,667 & 60,047 \\
4 & 1,222 & 4,527 & 64,574 \\
\hline
\end{tabular}

Ölçeğin faktör yapısını belirlemek üzere faktörlerin öz değerlerine dayalı olarak çizilen çizgi grafiği de incelenmiştir (bk. Şekil 1). Dikey eksenin öz değer miktarlarını, yatay eksenin ise faktörleri gösterdiği çizgi grafiğinde yüksek ivmeli ve hızlı düşüşün meydana geldiği görülmüştür. Çizgi grafiğinin yorumlanmasıyla da ölçek yapısının tek faktörlü olarak değerlendirilebileceği görüşü (Büyüköztürk, 2015, 136) dikkate alınmış ve yapının tek faktörlü olarak işleme alınmasına karar verilmiştir. 


\section{Şekil 1: Faktör Analizi Çizgi Grafiği (Scree Plot)}

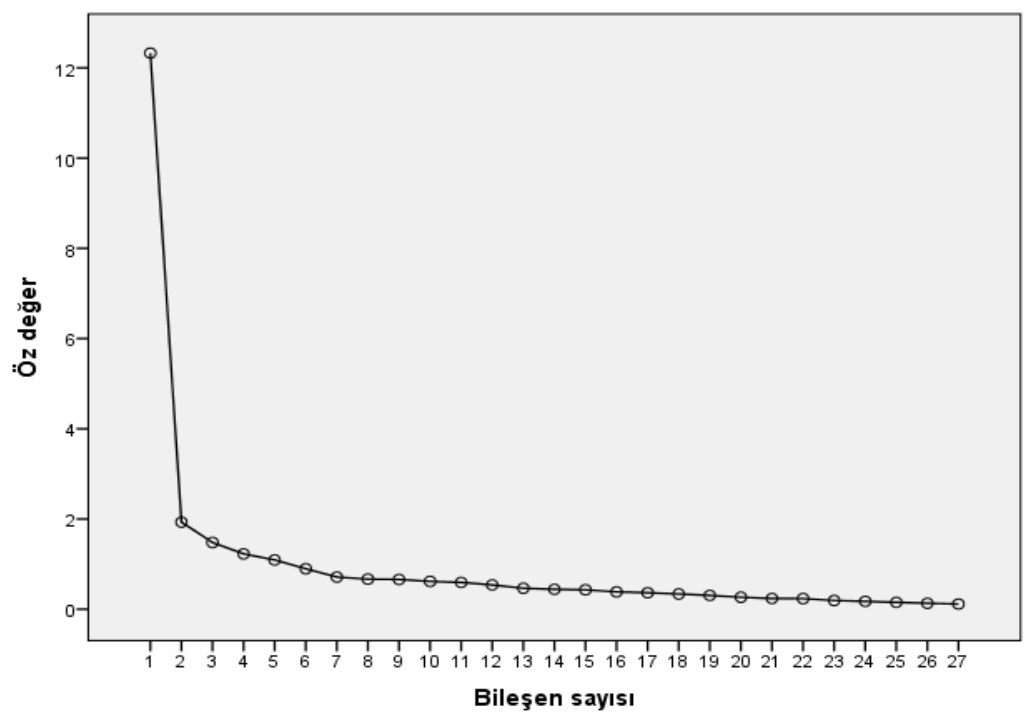

\section{Veri Analizi}

$\mathrm{Bu}$ araştırmada, çalışma grubundan elde edilen verilerin analiz edilmesinde SPSS paket programindan yararlanilarak betimsel ve kestirisel istatistikler yapılmıştır. Kestirisel istatistikler yapılmadan önce elde edilen veri setine hangi testlerin uygun olabileceğini belirlemek üzere verilerin normal dağılım gösterip göstermediği incelenmiştir.

Tablo 6: DKAB Tutum Ölçeğinin Değişkenlere Göre Normallik Test Sonuçlanı

\begin{tabular}{|c|c|c|c|c|}
\hline \multirow{2}{*}{ Değişken } & \multirow[b]{2}{*}{ Değişken Düzeyi } & \multirow[b]{2}{*}{$\mathbf{N}$} & \multicolumn{2}{|c|}{ Significance Değeri } \\
\hline & & & $\begin{array}{l}\text { Kolmogorov- } \\
\text { Smirnov }\end{array}$ & $\begin{array}{l}\text { Shapiro- } \\
\text { Wilk }\end{array}$ \\
\hline \multirow{2}{*}{ Cinsiyet } & $\mathrm{K}_{1 \mathrm{Z}}$ & 61 & 200 & ,065 \\
\hline & Erkek & 93 & ,200 & ,043 \\
\hline \multirow{4}{*}{ Sınıf Düzeyi } & 5. Sinif & 24 & 060 & ,061 \\
\hline & 6. Sinif & 17 & 200 & 391 \\
\hline & 7. Sinif & 19 & ,200 & ,476 \\
\hline & 9. Sinif & 25 & 200 & 230 \\
\hline
\end{tabular}


58 | C. TOSUN \& H. SÖZEN \& Y. İPEK \& V. ŞİMŞEK / Üstün Zekâlı Öğrencilerin Din Kültürü ve Ahlak Bilgisi Dersine İlişkin Tutumlarının İncelenmesi

\begin{tabular}{|c|c|c|c|c|}
\hline & 10. Sinif & 48 & ,200 & 697 \\
\hline & 11. Sinif & 26 & 200 & ,953 \\
\hline \multirow{2}{*}{$\begin{array}{c}\text { Anne Öğrenim } \\
\text { Düzeyi }\end{array}$} & Lise ve altı & 51 & 200 & , 123 \\
\hline & $\begin{array}{l}\text { Üniversite ve } \\
\text { lisansüstü }\end{array}$ & 108 & 200 & ,318 \\
\hline \multirow{2}{*}{$\begin{array}{c}\text { Baba Öğrenim } \\
\text { Düzeyi }\end{array}$} & Lise ve altı & 27 & 200 & ,139 \\
\hline & $\begin{array}{c}\text { Üniversite ve } \\
\text { lisansüstü }\end{array}$ & 132 & 200 & 251 \\
\hline \multirow{2}{*}{ Gelir Durumu } & Orta üstü & 55 & 200 &, 550 \\
\hline & Orta ve alt1 & 104 & ,200 & ,058 \\
\hline
\end{tabular}

${ }^{*} \mathrm{p}>, 05$

Tutum ölçeğinden elde edilen verilerin değişkenlere göre normal dağılım gösterip göstermediğini belirlemek üzere yapılan normallik testlerinin sonuçları tablo 6'da verilmiştir. Söz konusu testlerde, değişkenlerin sahip olduğu grup büyüklüğünün 29 ve üstü olması durumunda Kolmogorov-Smirnow; 29'dan az olması durumunda ise Shapiro-Wilk testi sonuçları kullanılır. Grubun büyüklüğüne göre tercih edilen Kolmogov-Smirnov ya da Shapiro-Wilk test sonucunun significance değerinin $0,05^{\prime}$ den büyük olması durumunda verilerin normal dağılım gösterdiği kabul edilir (Karagöz, 2016, 91-93). Tablo 6’da değişken gruplarının büyüklüğüne göre test sonuçlarına bakıldığında araştırma verilerinin normal dağılım sağladığı görülmektedir. Araştırmada bağımlı değişken ait verilerin eşit aralık ölçeğinde olması ve bağımlı değişken üzerinde etkisi araştırılan faktörün her düzeyinde normal dağılımın sağlanması; istatiksel işlemlerde parametrik testlerin kullanımının uygunluğunu göstermiştir. Buradan hareketle iki örneklem grubundan elde edilen ortalama değerleri kıyaslamak üzere ilişkisiz (bağımsız) örneklemler t-testi; ikiden fazla sayıda örneklem grubundan elde edilen ortalama değerleri kıyaslamak için tek faktörlü varyans analizi (ANOVA) testi kullanılmıştır.

Öğrencilerin DKAB dersine ilişkin tutum düzeylerinin değerlendirilebilmesi için değer aralıkları belirlenmiştir. Ölçekte her bir maddeye verilen görüş kodları 1 ile 5 arasında değiştiğinden aralıkların eşit olduğu varsayımından hareketle de 5-1/5 formülü kullanılmış ve puan aralıkları için 0,80 değeri bulunmuştur. Buna göre tutum düzeyi değerlendirmelerinde 1.00 - 1,79: hiç; 1.80 - 2.59: az; 2.60 - 3.39: orta; 3.40 
C. TOSUN \& H. SÖZEN \& Y. İPEK \& V. ŞIMŞEK / Analysing of the Attitudes of Gifted Students for the Course of Religious Culture and Ethics I 59

- 4.19: oldukça ve 4.20 - 5.00: tam şeklindeki puan aralıkları ve bunların karşıladığı düzeyler esas alınmıştır.

\section{Bulgular ve Tartışma}

Çalışmada kişisel bilgi formu ile Din Kültürü ve Ahlak Bilgisi Dersi Tutum Ölçeğinden elde edilen veriler analiz edilmiş ve değerlendirmeye tabi tutulmuştur. Araştırmada elde edilen bulgular ve bu bulgular ışığında yapılan değerlendirmeler bu başlık altında sunulmuştur.

Tablo 7: Öğrencilerin Din Kültürü ve Ahlak Bilgisi Dersi Tutum Ölçeğindeki İfadelere Katılım Düzeyleri

\begin{tabular}{|c|c|c|c|c|c|}
\hline \multirow[t]{2}{*}{$\begin{array}{l}\text { Din Kültürü ve Ahlak } \\
\text { Bilgisi Tutum Ölçeği } \\
\text { İfadeleri }\end{array}$} & \multirow[t]{2}{*}{$\mathbf{N}$} & \multicolumn{2}{|c|}{$\begin{array}{c}\text { Olumsuz } \\
\text { İfadeler } \\
\text { İçin } \\
\text { Normal } \\
\text { Kodlama }\end{array}$} & \multirow[t]{2}{*}{$\begin{array}{c}\text { Olumsuz } \\
\text { İfadeler } \\
\text { İçin Ters } \\
\text { Kodlama } \\
\mathbf{X}^{\mathbf{2}}\end{array}$} & \multirow[t]{2}{*}{$\begin{array}{l}\text { Tutum } \\
\text { Düzeyi }\end{array}$} \\
\hline & & $\mathbf{X}^{2}$ & S.S. & & \\
\hline $\begin{array}{l}{ }^{*} \text { DKAB dersinde kendimi } \\
\text { gergin hissederim. }\end{array}$ & 159 & 1,591 & 843 & 4,408 & Oldukça \\
\hline $\begin{array}{l}\text { *DKAB dersinde } \\
\text { zorlandığımı düşünürüm. }\end{array}$ & 159 & 1,742 & ,908 & 4,257 & Oldukça \\
\hline $\begin{array}{l}\text { *DKAB dersinin başlamasını } \\
\text { hiç istemem. }\end{array}$ & 159 & 1,817 & ,926 & 4,182 & Oldukça \\
\hline $\begin{array}{l}\text { *DKAB dersinde mutlu } \\
\text { olmam. }\end{array}$ & 159 & 1,924 & ,931 & 4,075 & Oldukça \\
\hline $\begin{array}{l}\text { *DKAB dersinde } \\
\text { öğrendiklerimi günlük } \\
\text { hayatta kullanabileceğimi } \\
\text { düşünmem. }\end{array}$ & 159 & 1,924 & 1,009 & 4,075 & Oldukça \\
\hline $\begin{array}{l}\text { *DKAB dersinin gereksiz bir } \\
\text { ders olduğuna inanırım. }\end{array}$ & 159 & 1,993 & 1,122 & 4,006 & Oldukça \\
\hline $\begin{array}{l}\text { DKAB dersinin ödevlerini } \\
\text { yaparım. }\end{array}$ & 159 & 3,962 & 1,072 & 3,962 & Oldukça \\
\hline DKAB dersini severim. & 159 & 3,949 & ,953 & 3,949 & Oldukça \\
\hline $\begin{array}{l}\text { DKAB dersinde kendimi } \\
\text { güvende hissederim. }\end{array}$ & 159 & 3,911 & ,983 & 3,911 & Oldukça \\
\hline $\begin{array}{l}{ }^{*} \text { DKAB dersinden zevk } \\
\text { almam. }\end{array}$ & 159 & 2,100 & 1,142 & 3,899 & Oldukça \\
\hline
\end{tabular}


60 । C. TOSUN \& H. SÖZEN \& Y. IPEK \& V. ŞIMŞEK / Üstün Zekâlı Öğrencilerin Din Kültürü ve Ahlak Bilgisi Dersine İlişkin Tutumlarının İncelenmesi

DKAB dersinde etkinliklere katılırım.

159

${ }^{*}$ Gelecekteki hayatımda

DKAB dersine ihtiyaç

duyacağıma inanmam.

*DKAB dersinin bir an önce bitmesini isterim.

DKAB dersinde öğretmenin anlattıklarını can kulağıyla dinlerim.

DKAB dersinin önemli bir ders olduğunu düşünürüm.

DKAB dersindeki konulara merak duyarım.

DKAB dersinde

öğrendiklerimi günlük hayatta uygularim.

DKAB dersinin benim için sıkıcı bir ders olduğunu düşünmem.

${ }^{*}$ DKAB dersi zorunlu ders olmasa almak istemem.

DKAB dersiyle ilgili daha çok şey öğrenmeye çabalarım.

${ }^{*}$ DKAB dersi ile ilgili ödev yapmaktan hoşlanmam.

DKAB dersinin bitmesini istemem.

DKAB dersinin başlamasını heyecanla beklerim.

DKAB ders kitaplarını ilgiyle okurum.

DKAB dersini diğer derslerden daha çok severim. Boş zamanlarımda DKAB dersine ilişkin bir şeyler okurum.
$159 \quad 2,113 \quad 1,190 \quad 3,886 \quad$ Oldukça

$159 \quad 2,132 \quad 1,097 \quad 3,867 \quad$ Oldukça

$159 \quad 3,779 \quad 1,022 \quad 3,779 \quad$ Oldukça

$159 \quad 3,691 \quad 1,124 \quad 3,691 \quad$ Oldukça

$159 \quad 3,685$,988 3,685 Oldukça

$159 \quad 3,660 \quad$ 946 3,660 Oldukça

$159 \quad 3,547 \quad 1,236 \quad 3,547 \quad$ Oldukça

$159 \quad 2,61 \quad 1,281 \quad 3,383 \quad$ Orta

$\begin{array}{lllll} & 359,308 & 1,136 & 3,308 & \text { Orta }\end{array}$

$159 \quad 2,735 \quad 1,203 \quad 3,264 \quad$ Orta

$159 \quad 3,025 \quad 1,136 \quad 3,025 \quad$ Orta

$159 \quad 3,000 \quad 1,102 \quad 3,000 \quad$ Orta

$159 \quad 2,528 \quad 1,205 \quad 2,528 \quad$ Orta

$159 \quad 2,402 \quad 1,000 \quad 2,402 \quad$ Orta

$159 \quad 2,264 \quad 1,104 \quad 2,264 \quad$ Orta 
C. TOSUN \& H. SÖZEN \& Y. İPEK \& V. ŞIMŞEK / Analysing of the Attitudes of Gifted Students for the Course of Religious Culture and Ethics I 61

DKAB dersini diğer derslere göre daha fazla çalışırım.

Hiç

Toplam

Oldukça

Araştırmada kullanılan ölçekte toplamda 27 ifade bulunmakta olup bunun 11'inin anlamca olumsuz olduğu tespit edilmiştir (Olumsuz ifadeler tablo $7^{\prime} \mathrm{de}^{*}$ işareti ile gösterilmiştir). Zira bazı ölçeklerde, maddelerin bir kısmı cevaplama sırasındaki eğilimleri engellemek adına anlamca olumsuz oluşturulmaktadır. Anlamca olumsuz bu maddelerin puanlarının ise, toplam puan hesaplanmadan önce tersine çevrilmemesinin gerekliliği belirtilmektedir (Pallant, 2017, 99). Bu bağlamda ölçeğin anlamca olumsuz olan 11 ifadesinde gerekli puan dönüşümleri gerçekleştirilmiştir.

Elde edilen veriler analize uygun hale getirildikten sonra öğrencilerin DKAB dersine ilişkin genel tutumuna ve tutumlarını ölçmek üzere kullanılan her bir ifadeye ait ortalama puanlar ve standart sapma değerleri hesaplanmış ve bunlara tablo 7 ' de yer verilmiştir.

Tablo 7 incelendiğinde öğrencilerin derse ilişkin genel tutumunun olumlu (oldukça düzeyinde) olduğu saptanmiştır. Araştırma bulgularımızı normal zekâ gelişim özellikleri gösteren öğrenciler üzerinde yapılan tutum çalışmaları ile karşılaştırdığımızda; üstün zekâlı öğrencilerin genel tutumunun genel profil ile benzerlik gösterdiği ortaya çıkmaktadır. Zira gerek çalışma grubumuzdaki öğrencilerin tutum ölçeğinden aldıkları ortalama puanlarının $\left(X^{2}=3.54\right)$, İpek $(2016)$ in çalışma grubundan elde ettiği ortalama puana $\left(X^{2}=3,33\right)$ yakın olması; gerekse Kaya (2001)'nın öğrencilerin DKAB dersine ilişkin tutumlarının genel olarak olumlu olduğu sonucuna ulaşması ve Selçuk (1990)'un öğretmenlerle gerçekleştirdiği çalışmasında öğrencilerin DKAB dersine ilişkin ilgilerinin çoğunlukla çok yüksek ve orta düzeyde olduğu sonucuna ulaşması bu yöndeki değerlendirmelerimizi desteklemektedir (İpek, 2016, 25; Kaya, 2001, 72; Selçuk, 2015, 126).

Öğrencilerin; DKAB dersine ilişkin tutumlarını ölçmek üzere kullanılan 27 maddenin 18'ine "yüksek (oldukça)", 8'ine "orta" ve 1 tanesine de "zayıf (hiç)" düzeyde sahip oldukları tespit edilmiştir. Ölçek maddelerinden en yüksek ortalama puanı olumsuz bir ifade olması açısından ters kodlama ile "DKAB dersinde kendimi gergin hissetmiyorum." şeklinde dönüştürülebileceğimiz maddenin; en düşük 
62 | C. TOSUN \& H. SÖZEN \& Y. İPEK \& V. ŞIMŞEK / Üstün Zekâlı Öğrencilerin Din Kültürü ve Ahlak Bilgisi Dersine İlişkin Tutumlarının İncelenmesi

ortalama puanı ise “DKAB dersini diğer derslere göre daha fazla çalışırım." şeklindeki maddenin aldığı ortaya çıkmıştır.

Tablo 7'deki veriler içerisinde öğrencilerin daha yüksek tutuma sahip olduğu maddeler dikkate alındığında; öğrencilerin genel anlamda DKAB dersini sevdikleri, dersi almaktan memnun oldukları, dersi sıkıcı görmedikleri, dersi ve ders sürecindeki etkinlikleri önemsedikleri, derste öğretilenleri kendileri için birer ihtiyaç olarak gördükleri ve ders sürecinde zorlanmadıkları anlaşılmaktadır.

Öğrencilerin daha düşük tutuma sahip olduğu maddeler incelendiğinde, hem ders kitaplarının öğrencilerin ilgisini çekmede, hem de derse ait ödevleri yapmakta orta düzeyde bir tutuma sahip oldukları görülmüştür. Öğrenciler, DKAB dersini diğer derslerle karşılaştırdıklarında, DKAB dersine daha az ilgi duyduklarını ve diğer derslere oranla daha az çalıştıklarını tutum ifadelerine yansıtmışlardır. Üstün zekâlı öğrencilerin DKAB dersine diğer derslerden daha az ilgi duyma durumlarını, bu öğrencilerin fen ve matematik alanlarında özel bir ilgi ve yeteneğe sahip olmaları (Camcı Erdoğan, 2018, 106; Barış Ecevit, 2019, 227); derse daha az çalışmalarını ise dersi anlamakta güçlük çekmeme durumlarıyla açıklamak mümkündür.

Tablo 8: Öğrencilerin DKAB Dersine İlişkin Tutumlarının Cinsiyet Durumu Değişkenine Göre İncelenmesi

\begin{tabular}{ccccccc}
\hline Cinsiyet & $\mathbf{N}$ & Ort. & S.S. & S.D. & $\mathbf{t}$ & $\mathbf{P}$ \\
K1z & 61 & 3,472 &, 626 & 152 &,- 770 &, 443 \\
Erkek & 93 & 3,561 &, 753 & & & \\
Toplam & 154 & & & & & \\
\hline \multicolumn{7}{c}{$\mathrm{p}<, 05$}
\end{tabular}

Öğrencilerin derse ilişkin tutumlarının cinsiyet durumlarına göre değişip değişmediğini ortaya koyabilmek için bağımsız örneklemler ttesti uygulanmıştır. Yapılan testin sonuçlarına göre kız ve erkek öğrencilerin derse ilişkin tutumları arasında istatistiksel olarak anlamlı bir farkın olmadığı görülmüştür $\left(t_{(152)}=-, 770 ; p>0,05\right)$.

Araştırmamızın cinsiyet durumuna ilişkin bulgularının; Kaya'nın “İlköğretim ve Ortaöğretim Öğrencilerinin Din Kültürü ve Ahlak Bilgisi Dersine Karşı Tutumları” (Kaya, 2001, 53), Arıcı'nın “Öğrencilerin İlköğretim Din Kültürü ve Ahlak Bilgisi Dersine Yönelik Tutumları (Arıc1, 2008, 171) ve İpek'in “Fen Lisesi Öğrencilerinin Din Kültürü ve 
Ahlak Bilgisi Dersine İlişkin Tutumları ve Değer Algıları (İpek, 2016, 110) adlı çalışmalarından elde edilen bulgularla uyum sağladiğ saptanmıştır. Ancak Zengin'in “Öğrencilerin Din Kültürü ve Ahlak Bilgisi Dersine Yönelik Tutumlarının Çeşitli Değişkenler Açısından İncelenmesi" adlı, 4-12. tüm sinıf düzeylerinin dâhil olduğu çalışmasında erkek öğrencilerin lehine olmak üzere cinsiyet durumuna göre gruplar arasında anlamlı bir farklılığın olduğu tespit edilmiştir (Zengin, 2003, 285).

Araştırma bulgularımız, normal zekâ gelişim özelliği gösteren öğrenciler üzerinde yapılan tutum çalışmaları ile karşılaştırıldığında; üstün zekâlı öğrencilerin cinsiyet durumu değişkenine göre derse ilişkin tutumlarının, çoğu araştırma bulgularıyla uyum sağladığı sonucuna ulaşılmıştır. Zira yapılan bilimsel çalışmaların genelinde cinsiyet değişkenin DKAB dersine ilişkin tutumlar üzerinde belirleyici olmadığ görülmektedir.

Öğrencilerin DKAB Dersine İlişkin Tutumlarının Sınıf Değişkenine Göre İncelenmesi

Tablo 9: Sınıf Düzeylerine İlişkin Bazı İstatistikler

\begin{tabular}{cccc}
\hline Sinıf Düzeyi & N & Ort. & S.S. \\
5. Sinıf & 24 & 3,978 &, 559 \\
6. Sinif & 17 & 3,442 &, 725 \\
7. Sinıf & 19 & 3,939 &, 554 \\
9. Sinıf & 25 & 3,841 &, 637 \\
10. Sinıf & 48 & 3,277 &, 536 \\
11. Sinif & 26 & 3,105 &, 808 \\
Toplam & 159 & 3,540 &, 707 \\
\hline
\end{tabular}

Tablo 10: Tek Faktörlü Varyans Analiz

\begin{tabular}{ccccccc}
\hline $\begin{array}{c}\text { Varyans } \\
\text { Kaynağı }\end{array}$ & $\begin{array}{c}\text { Kareler } \\
\text { Toplamı }\end{array}$ & S.D. & $\begin{array}{c}\text { Kareler } \\
\text { Ort. }\end{array}$ & F & P & $\begin{array}{c}\text { Gruplar Arası } \\
\text { Fark }\end{array}$ \\
$\begin{array}{c}\text { Gruplar } \\
\text { arası }\end{array}$ & 18,311 & 5 & 3,662 & 9,226 &, 000 & $\begin{array}{c}5 \text { ve 10, 11. sinıf } \\
7 \text { ve 10, 11. sinıf }\end{array}$ \\
Grup içi & 60,732 & 153 &, 397 & & & 9 ve 10, 11. sinıf \\
Toplam & 79,043 & 158 & & & & \\
\hline \multicolumn{7}{c}{$\mathrm{p}<, 05$}
\end{tabular}


64 | C. TOSUN \& H. SÖZEN \& Y. İPEK \& V. ŞIMŞEK / Üstün Zekâlı Öğrencilerin Din Kültürü ve Ahlak Bilgisi Dersine İlişkin Tutumlarının İncelenmesi

Öğrencilerin sınıf düzeyine göre DKAB dersine ilişkin tutumları arasında istatistiksel olarak anlamlı bir farklılı̆̆ın olup olmadığını ortaya koymak için Tek Faktörlü Varyans Analizi (ANOVA testi) yapılmıştır. Tek Faktörlü Varyans Analizi sonucunda sınıf düzeylerine göre öğrencilerin ortalama puanlarının en az ikisi arasında anlamlı bir farklılığın olduğu ortaya çıkmıştır $\left(F_{(5,153)}=9,226, p<, 05\right)$. Başka bir ifadeyle öğrencilerin sinıf düzeylerine göre derse ilişkin tutumları istatistiksel olarak anlamlı bir farklılık göstermektedir. Farklılığın hangi ikili gruplardan kaynaklandığını göstermek üzere çoklu karşılaştırma Tukey testi sonuçlarına bakılmıştır. Buna göre anlamlı farkın 5. sınıf öğrencilerinin lehine olmak üzere 5 ve 10, 11. sinıflar arasında; 7. sınıf öğrencilerinin lehine olmak üzere 7 ve 10, 11. sinıflar arasında; 9. sinıf öğrencilerinin lehine olmak üzere 9 ve 10, 11. sinıflar arasında olduğu görülmüştür.

Araştırmamızda sınıf düzeylerine göre alınan ortalama puanlar dikkate alındığında sınıf düzeyi yükseldikçe tutum puanlarının genel olarak düştüğü anlaşılmaktadır. Ancak araştırma bulgularımızda 6. sınıf düzeyindeki öğrencilerin bu genel duruma aykırı düştüğü görülmektedir. Bu bağlamda araştırma sonuçlarımızla birebir uyum sağlaması açısından Kaya'nın araştırmasında ulaştığı sonuçlar dikkat çekicidir. Zira Kaya'nın araştırma bulgularında da 7. sınıf öğrencilerinin lehine olmak üzere 7 ve 10, 11. sinıflar arasında; 9. sinıf öğrencilerinin lehine olmak üzere 9 ve 10, 11. sinıflar arasında anlamlı bir farkın olduğu tespit edilmiştir. Benzer şekilde 6 . sinıf öğrencilerinin ise 7,8 ve 9. sınıf öğrencilerinden daha düşük bir ortalama puana sahip olduğu ve dolayısıyla üst sınıflarla arasında anlamlı bir fark oluşturmadığı ortaya çıkmıştır (Kaya, 2001, 54).

Araştırma bulgularımızı destekleyen bir diğer araştırma bulgusu ise İpek'in fen lisesi öğrencileriyle gerçekleştirdiği çalışmasında geçmektedir. Söz konusu çalışmada da sinıf düzeyine göre gruplar arasında anlamlı bir farkın olduğu; en yüksek ortalama puanı 9. sınıf öğrencilerinin en düşük puanı ise 12. sınıf öğrencilerinin aldığı ortaya çıkmıştır (İpek, 2016, 111). Benzer şekilde Zengin'in araştırmasında da sınıf düzeyine göre gruplar arasında anlamlı bir farkın olduğu ve sinıf düzeyi yükseldikçe DKAB dersine yönelik olumlu tutumun azaldığı sonucuna ulaşılmıştır (Zengin, 2003, 285-286). Arıcı'nın çalışmasında ise sınıf düzeyleri arasında anlamlı bir farklılığa ulaşılmadığı tespit 
edilmiştir. Ancak bu durumu çalışmanın sadece birbirine çok yakın olan 6. ve 7. sınıf düzeylerini içermesi ile ilişkilendirmek mümkündür (Arıcı, 2008, 172).

Araştırma bulgularımızı, normal zekâ gelişim özellikleri gösteren öğrenciler üzerinde yapılan tutum çalışmaları ile karşılaştırdığımızda; üstün zekâlı öğrencilerin sınıf düzeyi değişkenine göre derse karşı tutumlarının genel profil ile yakın bir benzerlik gösterdiği, yani bu öğrencilerin de sinıf düzeyi yükseldikçe DKAB dersine ilişkin tutumlarının zayıfladığı görülmüştür.

Sınıf düzeyinin yükselmesinin özellikle lise düzeyine gelmiş öğrencilerin DKAB dersine ilişkin tutumlarında zayıflık oluşturmasının nedenlerinden biri K. E. Hyde'in Religious Learning in Adolescense adlı çalışmasında ulaştığı sonuçlara başvurarak açıklanabilir. Selçuk (2015)'un aktarımıyla; Hyde, çocukluk çağında dinî konulara ilginin yüksek olmasına rağmen, bu ilginin, sağlıklı bir yönlendirme olmazsa, zamanla azaldığını, gittikçe daha az öğrenme isteği duyulduğunu ve nihayet inkâr edici bir tutuma dahi dönebildiğini bu çalışmasında örneklerle ortaya koymuştur. Ayrıca Hyde'e göre; dine karşı ilgisizlik, tenkitçi düşüncenin ortaya çıktığ 1 zamana tesadüf etmekte ve dini gerçekler bir tahlile tabi tutulmadan karmaşıklığını muhafaza eder bir halde reddedilmektedir (Selçuk, 2015, 26-27).

Sınıf düzeyi ile DKAB dersine ilişkin tutum arasında karşıt bir ilişkinin olmasının bir diğer nedeni de Selçuk'a göre dini bilgilerin yaşanan dünya ile bağdaşmaması ve gençlerin dinsel öğretileri gereksiz değerlendirebilmeleridir. Çocukluk döneminde din eğitim ve öğretimi kültürel geçiş sağlanamazsa bazı gençlerin dinî malzemeyi çağdaş bulabileceği bazılarının ise mevcut durumun sürdürülmesinin gerekliliğinin savunucusu haline gelebilmektedir. Çocuğun ileride kendisini bekleyen soru dizelerine ve şüphelere hazır olması açısından din öğretimi programlarının onların gelişimine yardımcı olabilecek ve ihtiyaçlarına cevap verebilecek bir düzeyde olması gerekmektedir (Selçuk, 2015, 38). Benzer şekilde Altaş da, ortaöğretim öğrencilerinin bir şekilde gerçek hayat tecrübeleriyle ergenlikte ihtiyaç duyduğu ve konular arasında dinamik bir ilişki olması gerektiğini vurgulamaktadır (Altaş, 2004, 203). 
66 | C. TOSUN \& H. SÖZEN \& Y. İPEK \& V. ŞIMŞEK / Üstün Zekâlı Öğrencilerin Din Kültürü ve Ahlak Bilgisi Dersine İlişkin Tutumlarının İncelenmesi

Tablo 11: Öğrencilerin DKAB Dersine İlişkin Tutumlarının Gelir Durumu Değişkenine Göre İncelenmesi

\begin{tabular}{ccccccc}
\hline Gelir Düzeyi & $\mathbf{N}$ & Ort. & S.S. & S.D. & t & P \\
Orta ve Orta alt 1 & 104 & 3,618 &, 677 & & & \\
Orta üstü & 55 & 3,393 &, 745 & 157 & $-1,924$ &, 056 \\
$\quad$ Toplam & 159 & & & & & \\
\hline${ }^{*} \mathrm{p}<, 05$ & & & & & &
\end{tabular}

Öğrencilerin derse ilişkin tutumlarının, gelir düzeyi durumuna göre değişip değişmediğini ortaya koyabilmek için bağımsız örneklemler t-testi uygulanmıştır. Yapılan testin sonuçlarına göre öğrencilerin aile gelir durumunun, derse ilişkin tutum düzeyleri üzerinde istatistiksel olarak anlamlı bir farklılığa neden olmadığ görülmüştür $\left(\mathrm{t}_{(157)}=-1,924 ; \mathrm{p}>0,05\right)$.

(Kaya, 2001; Zengin, 2003; İpek, 2016) araştırmalarında sosyoekonomik düzey değişkeni ile derse ilişkin tutum düzeyi arasındaki ilişki incelenmiştir. Bu bağlamda Kaya'nın ve Zengin'in araştırmalarında öğrencilerin ailelerinin ekonomik durumunu yüksek, orta ve düşük olarak algılama durumlarına göre gruplar arasında önemli bir farkın olmadığ1 tespit edilmiştir (Kaya, 2001, 57; Zengin, 2003, 287). Ancak İpek'in araştırmasında gruplar arasında istatistiksel olarak anlamlı bir farklılığın olduğu sonucuna ulaşılmıştır. Söz konusu araştırmada ekonomik düzeyi orta ve orta altı olan öğrencilerin, ekonomik düzeyi orta üstü olan öğrencilerinden daha yüksek ortalama puanlara sahip olduğu ve dolayısıyla derse ilişkin daha olumlu bir tutuma sahip olduğu ortaya çıkmıştır (İpek, 2016, 113).

Araştırma bulgularımızda gelir değişkenine göre gruplar arası anlamlı bir fark çıkmamış olsa da İpek'in bulgularıyla benzer şekilde gelir durumu orta üstü olan öğrencilerin ortalama tutum puanlarının, gelir durumu orta ve orta altı olan öğrencilerden daha düşük olduğu görülmektedir. Nitekim Zengin'in araştırma bulgularında da gelir değişkeni gruplar arasında anlamlı bir fark yaratacak kadar önemli olmamakla birlikte öğrencilerin gelir düzeyi yükseldikçe derse ilişkin ortalama tutum puanlarında azalmanın olduğu tespit edilmiştir (Zengin, 2003, 287).

Araştırma bulgularımızı, normal zekâ gelişim özellikleri gösteren öğrenciler üzerinde yapılan tutum çalışmaları ile karşılaştırdığımızda; üstün zekâlı öğrencilerin gelir durumu değişkenine göre derse karşı 

the Course of Religious Culture and Ethics | 67

tutumlarının genel profil ile yakın bir benzerlik göstererek bu öğrencilerin de gelir düzeyi ile derse ilişkin tutumları arasında olumsuz bir ilişkinin olduğunu söylemek mümkündür.

Öğrencilerin aile gelir düzeyinin yükselmesi ile derse ilişkin tutumları arasındaki olumsuz ilişkinin nedenini anlamada Altaş (2004)'ın araştırması önemlidir. Zira Altaş “Öğrenci velilerinin ilköğretim Din Kültürü ve Ahlak Bilgisi derslerine karşı tutum düzeylerinin dinî tutum düzeyleriyle ilişkisi" adlı araştırmasında velinin sahip olduğu ekonomik düzeyin velinin kendisinin IDKAB dersine yönelik tutumlarını etkilediği sonucuna ulaşmıştır. Altaş'ın bu verileri 1şığında düşünüldüğünde velinin ekonomik düzeyinin, velinin kendisinin $\mathrm{DKAB}$ dersine ilişkin tutumunu etkilediği ve velinin tutumunun ise çocuğuna da yansıdığı çıkarımında bulunulabilir (Altaş, 2004, 104).

\section{Tablo 12: Öğrencilerin DKAB Dersine İlişkin Tutumlarının Anne Öğrenim Durumu Değişkenine Göre İncelenmesi}

\begin{tabular}{|c|c|c|c|c|c|c|}
\hline Öğrenim Düzeyi & $\overline{\mathbf{N}}$ & Ort. & S.S. & S.D. & $\bar{t}$ & $\bar{P}$ \\
\hline Lise ve altı & 51 & 3,643 & 728 & & & \\
\hline $\begin{array}{l}\text { Üniversite ve } \\
\text { üstü }\end{array}$ & 108 & 3,491 & 695, & 157 & 1,264 & 208 \\
\hline Toplam & 159 & & & & & \\
\hline
\end{tabular}

Öğrencilerin derse ilişkin tutumlarının, anne öğrenim düzeyi durumuna göre değişip değişmediğini ortaya koyabilmek için bağımsız örneklemler t-testi uygulanmıştır. Yapılan testin sonuçlarına göre öğrencilerin anne öğrenim durumunun, derse ilişkin tutumları üzerinde istatistiksel olarak anlamlı bir farklılığa neden olmadığı ortaya çıkmıştır $\left(\mathrm{t}_{(157)}=1,264 ; \mathrm{p}>0,05\right)$.

Anne öğrenim değişkenine göre derse ilişkin tutum düzeylerinin incelendiği (Kaya, 2001; Zengin, 2003; İpek, 2016) araştırmalarda ise grupların birbirinden anlamlı düzeyde farklılaştığ 1 tespit edilmiştir. Bu araştırmalara göre anne öğrenim durumu arttıkça öğrencilerin derse ilişkin tutum düzeylerinin genel olarak düştüğü; annesi üniversite mezunu olanların diğer gruplardan daha düşük ortalama puana sahip olmak üzere önemli ölçüde farklılaştı̆̆ı görülmektedir (Kaya, 2001, 57; Zengin, 2003, 288; İpek, 2016, 120). 
68 | C. TOSUN \& H. SÖZEN \& Y. İPEK \& V. ŞİMŞEK / Üstün Zekâlı Öğrencilerin Din Kültürü ve Ahlak Bilgisi Dersine İlişkin Tutumlarının İncelenmesi

Araştırma bulgularımızı, normal zekâ gelişim özellikleri gösteren öğrenciler üzerinde yapılan tutum çalışmaları ile karşılaştırdığımızda; üstün zekâlı öğrencilerin anne öğrenim durumunun genel olarak yüksek olmasından dolayı daha düşük eğitim düzeyine sahip olan gruplar oluşturulamamıştır. Lise ve altı şeklinde oluşturulan grubun da (51 kişi) sadece 13 tanesi ilköğretim mezunudur. Üstün zekâlı öğrencilerin anne öğrenim düzeylerinin genel profile göre yüksek ve birbirine yakın olması gruplar arasında anlamlı düzeyde farkın çıkmamasına neden olmuştur. Nitekim araştırmamızda anne öğrenim değişkenine göre grupların ortalama puanları incelendiğinde anne öğrenim düzeyi lise ve altı olan öğrencilerin, anne öğrenim düzeyi üniversite ve üstü olan gruptan daha olumlu bir tutuma sahip olduğu anlaşılmaktadır. Bu bağlamda anne öğrenim düzeyi değişkenine göre üstün zekâlı öğrencilerin tutumlarının genel profilden çok da farklılaşmadığını söylemek mümkündür.

Tablo 13: Öğrencilerin DKAB Dersine İlişkin Tutumlarının Baba Öğrenim Durumu Değişkenine Göre İncelenmesi

\begin{tabular}{|c|c|c|c|c|c|c|}
\hline Öğrenim Düzeyi & $\overline{\mathbf{N}}$ & Ort. & S.S. & S.D. & t & $\mathbf{P}$ \\
\hline Lise ve altı & 27 & 3,795 & ,742 & 157 & 2070 & 030 \\
\hline Üniversite ve üstü & 132 & 3,488 & 691 & $15 \%$ & 2,079 & (039, \\
\hline Toplam & 159 & & & & & \\
\hline
\end{tabular}

Öğrencilerin derse ilişkin tutumlarının, baba öğrenim düzeyi durumuna göre değişip değişmediğini ortaya koyabilmek için bağımsız örneklemler t-testi uygulanmıştır. Yapılan testin sonuçlarına göre öğrencilerin baba öğrenim durumunun, derse ilişkin tutumları üzerinde istatistiksel olarak anlamlı bir farklılığa neden olduğu ortaya çıkmıştır $\left(t_{(157)}=2,079 ; p<0,05\right)$. Gruplara ait ortalama puanlar karşılaştırıldığında; baba öğrenim düzeyi en çok lise olan öğrencilerin ortalama tutum puanlarının $\left(X^{2}=3,795\right)$, baba öğrenim düzeylerinin en az üniversite olan öğrencilerin ortalama tutum puanlarından $\left(X^{2}=3,488\right)$ daha yüksek olduğu görülmüştür.

Araştırmamızda babanın eğitim düzeyinin öğrencilerin derse ilişkin tutum düzeyleri üzerinde olumsuz bir etkide bulunduğu görülmektedir. Bu bağlamda Kaya'nın araştırmasında da gruplar arası anlamlı farkın bulunduğu, en düşük puanı babası yükseköğretim mezunu olan öğrencilerin aldığı ve bu grubun babası ilkokul mezunu 

the Course of Religious Culture and Ethics I 69 olan öğrencilerle önemli ölçüde farklılaştığı tespit edilmiştir (Kaya, 2001, 58). Benzer şekilde Zengin'in araştırmasında da en yüksek ortalama tutum puanını babası ilkokula gitmemiş grubun aldığı, en düşük ortalama puanı ise babası üniversite mezunu olan grubun aldığı ortaya çıkmıştır. Ayrıca söz konusu araştırmada da babası üniversite mezunu olan grubun diğer tüm gruplarla önemli düzeyde farklılaştığ 1 görülmektedir (Zengin, 2003, 288). Aynı duruma İpek' in araştırmasında da rastlanılmaktadır. Buna göre gruplar arasında anlamlı farkın baba öğrenim düzeyi üniversite mezunu olan grup ile baba öğrenim düzeyi ilkokul, ortaokul ve lise mezunu olan öğrenciler arasında çıktığı ve en düşük ortalama tutum puanını, babasının öğrenim düzeyi üniversite mezunu olan öğrencilerin aldığı görülmektedir (İpek, 2016, 121).

Araştırma bulgularımızı, normal zekâ gelişim özellikleri gösteren öğrenciler üzerinde yapılan tutum çalışmaları ile karşılaştırdığımızda ise; üstün zekâlı öğrencilerin baba öğrenim durumu değişkenine göre derse karşı tutumlarının genel profil ile yakın bir benzerlik göstererek baba öğrenim düzeyi yükseldikçe derse ilişkin tutumunun zayıfladığını söylemek mümkündür.

Ebeveynlerin öğrenim düzeyi ile öğrencilerin derse ilişkin tutumları arasında çoğunlukla olumsuz bir ilişkinin görülmesinin olası nedenleri; ebeveynlerin öğrenim düzeyinin; din algıları, dini tutumları ve din eğitiminden beklentileri üzerinde değişim ve dönüşüm yaratmasıyla ilişkili düşünülebilir. Zira öğrenim düzeyi ve dini eğilim/alg1/tutum ilişkisinin incelendiği araştırmalarda bireyin öğrenim düzeyi yükseldikçe dini davranış ve tutum puanlarının zayıfladığı veya bireyde sekülerleşmenin arttığ1 yönündeki sonuçlara ulaşılan araştırmalar yoğunluktadır (Çelik, 2003, 164, 171; Akbolat, 2014, 83; Aydemir, 2008, 52; Arslan, 2008, 107; Uysal, 1995, 269). Öğrenim düzeyi ile dini eğilim arasında karşıt yönde bir ilişkinin olması durumunun nedenleri ise, bireylerin bilimsel ve rasyonel bilgi düzeyine göre yeni ve farklı düşünme tarzları geliştirmeleri (Akbolat, 2014, 83), özellikle üniversite öğreniminde hem farklı kültürlerle hem de geleneksel anlamlandırma sistemlerinden farklı anlam sistemleriyle karşılaşmaları olarak sıralanabilir (Çelik, 2003, 171). 
70 । C. TOSUN \& H. SÖZEN \& Y. İEK \& V. ŞIMŞEK / Üstün Zekâlı Öğrencilerin Din Kültürü ve Ahlak Bilgisi Dersine İlişkin Tutumlarının İncelenmesi

\section{Sonuç ve Öneriler}

$\mathrm{Bu}$ araştırmada üstün zekâlı öğrencilerin DKAB dersine ilişkin genel tutumlarının ne yönde olduğu ve genel tutumlarının çeşitli değişkenlere göre farklılaşıp farklılaşmadığı incelenmiştir. Araştırmada elde edilen bulgular, ilgili literatür ışı̆̆ında tartışılmıştır. Yapılan tespit ve değerlendirmelerden hareketle araştırmada ulaşılan sonuçlar ve geliştirilen öneriler şu şekilde sıralanabilir:

- Ǘstün zekâlı öğrencelerin DKAB dersine ilişkin genel tutumları olumludur ve normal zekâ gelişim özelliği gösteren öğrencilerin tutumlarıyla benzerlik göstermektedir.

- Üstün zekâlı öğrencilerin genel anlamda DKAB dersini sevdikleri, dersi almaktan memnun oldukları, dersi sıkıcı bulmadıkları, dersi ve ders sürecindeki etkinlikleri önemsedikleri, derste öğretilenleri kendileri için birer ihtiyaç olarak gördükleri ve ders sürecinde zorlanmadıkları sonucuna ulaşılmıştır.

- $\quad$ DKAB ders kitaplarının üstün zekâlı öğrencilerin ilgilerini çekme açısından orta düzeyde kaldığı tespit edilmiştir. Bunun yanında diğer bazı derslere kıyasla bu derse daha az ilgi duydukları saptanmıştır. Bu durum, öğrencilerin din ve ahlak öğretimi alanına duydukları ilgi ve ihtiyaçlarının belirlenmesinin gerekliliğini bir kez daha ortaya koymaktadır. Bu noktada öğrencilerin ders kitaplarıyla ilgili eleştiri ve beklentilerinin göz önünde bulundurulması önem arz etmektedir.

- Öğrencilerin DKAB dersine ilişkin ödevleri yapmakta orta düzeyde bir tutuma sahip oldukları ve bu derse diğer derslere oranla daha az çalıştıkları sonucuna ulaşılmıştır. Öğrencilerin ödev yapma ve/veya ders çalışma konusundaki tutumlarının, derse ilişkin genel tutumlarına göre daha düşük olması durumunu öğrencilerin öğrenme hızları ile ilişkilendirmek de mümkündür. Ancak bu durumun olası nedenlerini saptamak üzere nicel araştırmaların yanı sıra nitel araştırmalara da ihtiyaç vardır.

- Üstün zekâlı öğrencilerin derse ilişkin tutumlarının cinsiyet durumuna göre anlamlı düzeyde farklılaşmadı̆̆ ortaya çıkmıştır. Araştırmada bu yönde elde edilen bulguların, normal zekâ gelişim özelliği gösteren öğrenciler üzerinde gerçekleştirilen diğer tutum çalışmalarıyla karşılaştırılması sağlanmıştır. Yapılan karşılaştırmalar neticesinde cinsiyet değişkeninin öğrencilerin DKAB 

the Course of Religious Culture and Ethics I 71

dersine ilişkin tutumları üzerinde çoğunlukla belirleyici olmadığı görülmüştür.

- Üstün zekâlı öğrencilerin sinıf düzeylerine göre derse ilişkin tutumları arasında anlamlı bir farklılı̆̆ın olduğu ortaya çıkmıştır. Buna göre anlamlı farkın 5. sınıf öğrencilerinin lehine olmak üzere 5 . ve 10 . ile 5 . ve 11 . siniflar arasinda; 7. sinıf öğrencilerinin lehine olmak üzere 7 . ve 10 . ile 7 . ve 11 . sinıflar arasında; 9. sınıf öğrencilerinin lehine olmak üzere 9. ve 10. ile 9. ve 11. sinıflar arasında olduğu tespit edilmiştir. Buna göre, üstün zekâlı öğrencilerin sınıf düzeyi değişkenine göre derse karşı tutumlarının normal zekâ gelişim özelliği gösteren öğrenciler ile yakın bir benzerlik gösterdiğine, yani bu öğrencilerin de sınıf düzeyi yükseldikçe DKAB dersine ilişkin tutumlarının zayıfladığına ulaşılmıştır.

- Üstün zekâlı öğrencilerin aile gelir durumu değişkeni ile derse ilişkin tutumları arasında anlamlı bir farklılığın olmadığı ortaya çıkmıştır. Araştırmadan elde edilen bulgular, normal zekâ gelişim özelliği gösteren öğrenciler üzerinde yapılan diğer tutum çalışmalarıyla karşılaştırıldığında ise; öğrencilerin, aile gelir durumlarının derse ilişkin tutumları üzerinde anlamlı bir farklılık yaratması noktasında çalışmalar arasında tutarlılı̆̆ın olmadığı tespit edilmiştir. Aile gelir düzeyi yüksek olan öğrencilerin gelir durumu düşük olan öğrencilerden derse ilişkin daha zayıf bir tutuma sahip olduğu noktasında ise çalışmalar arasında genel olarak bir tutarlılığın olduğu ortaya çıkmıştır. Bu araştırmada da öğrencilerin aile gelir durumunun, DKAB dersine ilişkin tutumları üzerinde anlamlı bir farklılık yaratacak kadar belirleyici olmamakla birlikte gelir durumunun yükselmesinin öğrencilerin tutumlarını olumsuz yönde etkilediği saptanmıştır.

- Üstün zekâlı öğrencilerin anne öğrenim düzeyi değişkenine göre derse ilişkin tutumları arasında anlamlı bir farklılığın olmadığı tespit edilmiştir. Diğer tutum çalışmalarıyla karşılaştırıldığında ise; üstün zekâlı öğrencilerin anne öğrenim düzeyinin genel olarak normal zekâ gelişim özelliği gösteren öğrencilerin anne öğrenim düzeyinden yüksek olduğu görülmüştür. Diğer bazı çalışmalarda anne öğrenim düzeyi okur-yazar, ilkokul ve ortaokul mezunu şeklinde meydana getirilen değişken grupları 
72 । C. TOSUN \& H. SÖZEN \& Y. İPEK \& V. ŞIMŞEK / Üstün Zekâlı Öğrencilerin Din Kültürü ve Ahlak Bilgisi Dersine İlişkin Tutumlarının İncelenmesi

araştırmamızda yeterli sayıya ulaşılmadığından oluşturulamamıştır. Çalışma grubumuzdaki öğrencilerin anne öğrenim düzeylerinin genel profile göre yüksek ve birbirine yakın olması öğrencilerin derse ilişkin tutumları üzerinde söz konusu değişkenin etkisinin değerlendirilmesini sınırlandırmıştır. Nitekim araştırmamızda öğrencilerin anne öğrenim durumunun, DKAB dersine ilişkin tutumları üzerinde anlamlı bir farklılık yaratacak kadar belirleyici olmamakla birlikte anne öğrenim durumunun yükselmesinin öğrencilerin tutumlarını olumsuz yönde etkilediği belirlenmiştir.

- Üstün zekâlı öğrencilerin baba öğrenim düzeyi değişkenine göre derse ilişkin tutumları arasında anlamlı bir farklılığın olduğu ortaya çıkmıştır. Buna göre baba öğrenim düzeyi en çok lise olan öğrencilerin ortalama tutum puanlarının, baba öğrenim düzeylerinin en az üniversite olan öğrencilerin ortalama tutum puanlarından daha yüksek olduğu görülmüştür. Araştırma bulgularımızı, normal zekâ gelişim özelliği gösteren öğrenciler üzerinde yapılan diğer DKAB dersi tutum çalışmalarıyla karşılaştırdığımızda ise; üstün zekâlı öğrencilerin baba öğrenim durumu değişkenine göre derse karşı tutumlarının genel profil ile yakın bir benzerlik gösterdiği; baba öğrenim durumunun yükselmesinin öğrencilerin derse ilişkin tutumları üzerinde olumsuz bir etkide bulunduğu sonucuna ulaşılmıştır.

Sonuç olarak; üstün zekâlı öğrencilerin de normal zekâ gelişim özelliği gösteren öğrenciler gibi sınıf düzeylerinin, aile gelir durumlarının ve ebeveyn öğrenim durumlarının yükselmesinden olumsuz etkilendiği saptanmıştır. Gerek üstün zekâlı öğrencilerin, gerekse normal zekâ gelişim özelliği gösteren öğrencilerin DKAB dersine ilişkin tutum düzeylerini olumlu yönde arttırmak amacıyla öğrencilerin kendilerinin ve velilerinin dersin öğretim programından, öğretmenlerinden, öğretim etkinliklerinden, materyallerinden ve yöntem-tekniklerinden beklentilerinin neler olduğunun tespit edilmesi ve söz konusu hususların gözden geçirilmesi ve iyileştirilmesi açısından önemlidir.

$\mathrm{Bu}$ çalışmanın sonucunda öncelikli olarak önerilen husus elde edilen nicel bulguların desteklenmesini ve açıklanmasını sağlamak üzere nitel çalışmaların yapılmasıdır. Bu doğrultuda önerilen bir diğer önemli husus ise ilgili araştırmalardan elde edilen tespit ve öneriler göz 

the Course of Religious Culture and Ethics | 73

önünde bulundurularak üstün zekâlı olarak tanılanmış öğrencilere yönelik farklılaştırılmış DKAB öğretim programlarının geliştirilmesidir. Üstün zekâlı öğrencilere yönelik eğitsel faaliyetlerin bir bütünlük içerisinde yürütülmesini sağlamak üzere öğrenme kapasitelerini, üst düzey düşünme becerilerini, ilgi ve ihtiyaçlarını dikkate alan ders materyallerinin geliştirilmesi de ihmal edilmemelidir. Üstün zekâlı öğrencilere yönelik tasarlanacak tüm eğitsel faaliyetlerde bilgiyi hazır sunan değil, bilgiyi yapılandırmayı mümkün kılacak yaklaşım, yöntemteknik ve materyallerin seçilmesine ve geliştirilmesine özen gösterilmelidir.

\section{Kaynakça}

Akarsu, Füsun. Üstün Yetenekli Çocuklar, Aileleri ve Sorunları. Ankara: Eduser Yayınları, 2001.

Akbolat, Abdurrahman. Yaşlılık Döneminde Yaşam Kalitesi ve Dindarlık İlişkisi. Konya: Necmettin Erbakan Üniversitesi, Sosyal Bilimler Enstitüsü, Yayınlanmamış Yüksek Lisans Tezi, 2014.

Altaş, Nurullah. Gençlik Döneminde Din Olgusu ve Liselerde Din Öğretimi. Ankara: Nobel Yayıncılık, 2014.

Altaş, Nurullah. “Öğrenci Velilerinin İlköğretim Din Kültürü ve Ahlak Bilgisi Derslerine Karşı Tutum Düzeylerinin Dini Tutum Düzeyleriyle İlişkisi (Ön Araştırma)". Ankara Üniversitesi İlahiyat Fakültesi Dergisi 45/1 (2004), 85-105.

Arıc1, İsmail. "Öğrencilerin İlköğretim Din Kültürü ve Ahlak Bilgisi Dersine Yönelik Tutumları". Fırat Üniversitesi İlahiyat Fakültesi Dergisi 13/1 (2008), 161-175.

Arslan, Hasan. Ekonomik Kalkınmada Dinsel Tutum ve Davranışların Çift Yönlü Rolü. İzmir: Dokuz Eylül Üniversitesi, Sosyal Bilimler Enstitüsü, Yayınlanmamış Doktora Tezi, 2008.

Atik, Aslıhan. "Dini Gelişim Kuramlarına Din Eğitimi Bağlamında Genel Bir Bakış". İnsan ve Toplum Bilimleri Araştırmaları Dergisi 4/3 (2015), 728-743.

Aydemir, Rüveyda Efdal. Dindarlık ve Mutluluk İlişkisi. Samsun: Ondokuzmayıs Üniversitesi, Sosyal Bilimler Enstitüsü, Yayınlanmamış Yüksek Lisans Tezi, 2008. 
74 । C. TOSUN \& H. SÖZEN \& Y. İPEK \& V. ŞIMŞEK / Üstün Zekâlı Öğrencilerin Din Kültürü ve Ahlak Bilgisi Dersine İlişkin Tutumlarının İncelenmesi

Barış, Nazlı - Ecevit, Tuğba. “Özel Yetenekli Öğrencilerin Eğitiminde STEM Uygulamaları". Ĕgitim Fakültesi Elektronik Fen ve Matematik Eğitimi Dergisi 13/1 (2019), 217-233.

Bayraktar, Mehmet Faruk. İbn Cemaa'dan Öğretmen ve Öğrencilere Öğ̈̈tler. İstanbul: Marmara Üniversitesi İlahiyat Vakfı Yayınları, 2015.

BİLSEMY, Bilim ve Sanat Merkezleri Yönergesi (Kanun No. 2742). Milli Eğitim Bakanlığı, 2015.

Büyüköztürk, Şener. Sosyal Bilimler İçin Veri Analizi El Kitabı. Ankara: Pegem Akademi Yayıncilık, 2015.

Camcı Erdoğan, Sezen. "Fen Bilimleri Alanında Özel Yetenekli Öğrenciler ve Müfredatın Farklılaştırılması". Özel Yetenekli Öğrenciler ve Eğitimleri. ed. Feyzullah Şahin. 105-135. Ankara: Anı Yayınları, 2018.

Clark, Barbara. Üstün Zekâlı Olarak Büyümek: Evde ve Okulda Çocuklarm Potansiyellerini Geliştirmek. çev. Fatih Kaya vd.. Ankara: Nobel Akademik Yayıncilık, 2015.

Creswell, John W. Eğitim Araştırmalarl; Nitel ve Nicel Araştırmanın Planlanması, Yürütülmesi ve Değerlendirilmesi. İstanbul: Edam Yayınlar1, 2017.

Çatalbaş, A. S. Üstün Yetenekli Öğrencilerin Yetkinlik Beklentileri. Kocaeli: Kocaeli Üniversitesi, Sosyal Bilimler Enstitüsü, Yayınlanmamış Yüksek Lisans Tezi, 1998.

Çelik, Celaleddin. "Değişkenler ve Boyutlar Bağlamında Türkiye Toplumunda Dini Hayat". Bilimname 2003/1 (2003), 153-154.

Erkuş, Adnan. Psikolojide Ölçme ve Ölçek Geliştirme-I. Ankara: Pegem Akademi Yayıncılık, 2016.

Frei, Shelly - Conklin, Wendy. Üstün Zekâlı ve Yetenekliler İçin Eğitim Programının Farklılaştırılması: Başarılı Sinıflar İçin Profesyonel Gelişim. çev. Nihat Gürel Kahveci. İstanbul: Özgür Yayınları, 2016.

Güçin, Gökhan - Oruç, Şahin. “Türkiye'de Üstün Yetenekliler ve Yetenekliler Alanında Yapılmış Akademik Çalışmaların Çeşitli Değişkenler Yönünden İncelenmesi". Adıyaman Üniversitesi Eğitim Bilimleri Dergisi (2015), 113-135.

Gündüz, Turgay. "Üstün Zekâlı Çocuklarda Ahlâk Gelişimi ve Eğitimi". İstanbul Üniversitesi İlahiyat Fakültesi Dergisi 1/1 (2010), 157-177. 
C. TOSUN \& H. SÖZEN \& Y. İPEK \& V. ŞIMSŞEK / Analysing of the Attitudes of Gifted Students for the Course of Religious Culture and Ethics I 75

Gündüz, Turgay. “Üstün Zekalı veya Özel Yetenekli Bireylerde Din Eğitimi". Özel Eğitimde Din Eğitimi. ed. Saadettin Özdemir Mustafa Başkonak. 238-276. Ankara: Grafiker Yayınları, 2008.

Güngör, Erol. Ahlak Psikolojisi ve Sosyal Ahlak. İstanbul: Ötüken Yayınları, 2008.

Gürbüz, Sait - Şahin, Faruk. Sosyal Bilimlerde Araştırma Yöntemleri (Felsefe-Yöntem-Analiz). Ankara: Seçkin Yayıncılık, 2014.

İpek, Yasemin. Fen Lisesi Öğrencilerinin Din Kültürü ve Ahlak Bilgisi Dersine İlişkin Tutumları ve Değer Algıları. Diyarbakır: Dicle Üniversitesi, Sosyal Bilimler Enstitüsü, Yayınlanmamış Yüksek Lisans Tezi, 2016.

İslamoğlu, Hamdi - Alnıaçı, Ümit. Sosyal Bilimlerde Araştırma Yöntemleri. İstanbul: Beta Yayıncılık, 2016.

Karagöz, Yalçın. İstatistiksel Analizler. Ankara: Nobel Yayıncılık, 2016.

Kaya, Mevlüt. "İlköğretim ve Ortaöğretim Öğrencilerinin Din Kültürü ve Ahlak Bilgisi Dersine Karşı Tutumları". Ondokuz Mayıs Üniversitesi İlahiyat Fakültesi Dergisi 12/12-13 (2001), 43-78.

Kirk, Samuel vd.. Educating Exceptional Children. USA: Haughton Mifflin Company, 1989.

MEB. Birinci Özel Eğitim Konseyi Ön Raporu. Ankara: Millî Eğitim Bakanlığı Yayınları, 1991.

Neumeister, Kristie L. Speirs vd.. “Fourth-Grade Teachers' Perceptions of Giftedness: Implications for Identifying and Serving Diverse Gifted Students". Journal for the Education of the Gifted 30/4 (2007), 479-499.

Özdemir, Şuayip - Çelik, Rahime. “Din Kültürü ve Ahlak Bilgisi Dersi Tutum Ölçeğinin Geçerlik ve Güvenirlik Çalışması". Amasya Üniversitesi İlahiyat Fakültesi Dergisi 8 (2017), 7-20.

Özel Yetenekli Bireyler Strateji ve Uygulama Planı 2013 - 2017. Ankara: MEB Özel Eğitim ve Rehberlik Hizmetleri Genel Müdürlüğü, 2013. Pallant, Julie. SPSS Kullanma Kılavuzu. çev. Sibel Balcı - Berat Ahi. Ankara: Anı Yayıncilık, 2017.

Selçuk, Mualla. Çocuğun Eğitiminde Dini Motifler. Ankara: TDV Yayınları, 2015.

Şimşek, Ali. Öğretim Tasarımı. Ankara: Nobel Yayın Dağıtım, 2009.

TDK, “Türk Dil Kurumu Büyük Türkçe Sözlük”. 2020. https://sozluk.gov.tr/. Erişim tarihi:10.10.2020. 
76 | C. TOSUN \& H. SÖZEN \& Y. İEK \& V. ŞIMŞEK / Üstün Zekâlı Öğrencilerin Din Kültürü ve Ahlak Bilgisi Dersine İlişkin Tutumlarının İncelenmesi

Tosun, Cemal. Din Eğitimi Bilimine Giriş. Ankara: Pegem Akademi Yayıncilık, 2012.

Uysal, Veysel. "İslami Dindarlık Üzerinde Pilot Bir Çalışma". Jorunal of Islam in Research 8/3-4 (ts.), 263-271.

Winebrenner, S. "Gifted Students Need an Education, Too". Educational Leadership 17 (2000), 52-56.

Zengin, Mahmut. "Öğrencilerin Din Kültürü ve Ahlak Bilgisi Dersine Yönelik Tutumlarının Çeşitli Değişkenler Açısından İncelenmesi". Değerler Ĕ̆itimi Dergisi 11/25 (2003), 271-301. 